\title{
Recent advances in metal-free catalysts for the synthesis of cyclic carbonates from $\mathrm{CO}_{2}$ and epoxides
}

\author{
Dong-Hui Lan a, Na Fan a, Ying Wang a, Xian Gao a, Ping Zhang a, Lang Chen a, Chak-Tong Au a,b, \\ Shuang-Feng Yin a,* \\ a State Key Laboratory of Chemo/Biosensing and Chemometrics, College of Chemistry and Chemical Engineering, Hunan University, Changsha 410082, \\ Hunan, China \\ ${ }^{\mathrm{b}}$ College of Chemistry and Chemical Engineering, Hunan Institute of Engineering, Xiangtan 411104, Hunan, China
}

\section{A R T I C L E I N F O}

Article history:

Received 1 March 2016

Accepted 22 March 2016

Published 5 June 2016

\section{Keywords:}

Cycloaddition

Carbon dioxide

Epoxide

Cyclic carbonate

Metal-free catalyst

Synergy

\begin{abstract}
A B S T R A C T
The aim of "green chemistry" and "atom economy" is to utilize carbon dioxide and replace harmful reactants such as $\mathrm{CO}$ and phosgene for the production of cyclic carbonates. In this paper, metal-free catalysts including organic bases, ionic liquids, supported catalysts, organic copolymers and carbon materials for the synthesis of cyclic carbonates by the cycloaddition of carbon dioxide to epoxides are reviewed. Recent advances in the design of the catalysts and the understanding of the reaction mechanism are summarized and discussed. The synergistic effects of organic bases and hydrogen bond donors, organic bases and nucleophilic anions, hydrogen bond donors and nucleophilic anions and active components and supports are highlighted. The challenge is to develop metal-free catalysts suitable for carbon dioxide capture and fixation. The ultimate goal is to synthesize cyclic carbonates in a flow reactor directly using carbon dioxide from industrial flue gas at ambient temperature and atmospheric pressure. By using synergetic effects, a multi-functional approach can meet the design strategy of metal-free catalysts for carbon dioxide adsorption and activation as well as epoxide ring opening.
\end{abstract}

(C) 2016, Dalian Institute of Chemical Physics, Chinese Academy of Sciences. Published by Elsevier B.V. All rights reserved.

\section{Introduction}

The concentration of carbon dioxide $\left(\mathrm{CO}_{2}\right)$ in the atmosphere is unprecedentedly high [1,2]. The valorization of $\mathrm{CO}_{2}$ has attracted much attention not only because of global warming but also because of the potential use of $\mathrm{CO}_{2}$ as a safe, abundant, renewable and inexpensive $\mathrm{C} 1$ source for the formation of valuable chemicals [3-6]. However, $\mathrm{CO}_{2}$ is kinetically and thermodynamically stable because of the stable $\mathrm{C}=0$ bond distance $(0.116 \mathrm{~nm})$ which is shorter than the normal $\mathrm{C}=0$ bond length, and it is hard to activate $[7,8]$. In other words, a large energy input is required to transform $\mathrm{CO}_{2}$. It is known that using high-energy starting materials such as small-membered ring compounds for the formation of oxidized low-energy synthetic targets is an effective methodology for $\mathrm{CO}_{2}$ utilization [9]. As unstable three-membered heterocycles, epoxides can be activated by ring opening under mild conditions $[10,11]$. In addition, epoxides are important industrial substrates easily accessible from olefins $[10,11]$. From the viewpoint of "green chemistry" and "atom economy", it is desirable to perform cy-

\footnotetext{
* Corresponding author. Tel/Fax: +86-731-88821171; E-mail: sf_yin@hnu.edu.cn This work was supported by the National Science and Technology Support Project of China (2013BAC11B03), the National Natural Science Foundation of China (21401054, 21476065, 21273067), and the Graduate Student Scientific Research Innovation Fund Project of Hunan Province (CX2015B082).
}

DOI: 10.1016/S1872-2067(15)61085-3 | http://www.sciencedirect.com/science/journal/18722067 | Chin. J. Catal., Vol. 37, No. 6, June 2016 
cloaddition of $\mathrm{CO}_{2}$ with epoxides for the synthesis of cyclic carbonates for use as aprotic solvents, high-permittivity electrolyte components, as well as raw materials for the synthesis of polycarbonates $[12,13]$.

Generally, $\mathrm{CO}_{2}$ is considered an electrophile because the electrophilicity of the carbon atom is higher than the nucleophilicity of the oxygen atoms $[14,15]$. The adsorption and activation of $\mathrm{CO}_{2}$ normally occur on basic substrates [16,17]. Owing to the weak basicity of epoxides, the ring opening of epoxides commonly requires a Lewis acid and a nucleophile [18-24]. Various well-defined and selective catalysts have been developed for the cycloaddition of $\mathrm{CO}_{2}$ to epoxides. These are homogeneous catalysts such as metal salts [18], organic bases [16], ionic liquids (ILs) [19] and metal complexes [20], as well as heterogeneous catalysts including metal oxides [21], supported catalysts [22], organic copolymers [23], metal-organic frameworks [24] and carbon materials [25].

There are a number of recent reviews on catalysts for the cycloaddition of $\mathrm{CO}_{2}$ to epoxides [26-32]. Comerford et al. [30] summarized the homogeneous metal-based catalysts restricted to metals that are abundant: sodium, potassium, aluminum, calcium, titanium and iron. They discussed the merits and limitations of the catalyst systems. Martín and coworkers [31] gave a concise overview of homogeneous metal-containing systems. D'Elia et al. [11] reviewed the actions of group III-V transition-metal complexes as Lewis acids for cycloaddition in the homogeneous and heterogeneous phases. As metal-free catalysts, ILs have been discussed in several recent reviews but there is no comprehensive overview that focuses specifically on metal-free catalysts [26,27]. Moreover, the global supplies of the most used metals are decreasing alarmingly. Furthermore, the supplies of some metals are restricted to a small number of geographical areas, and the recycling rates for many metals are low. As a result, there are many elements that are considered "endangered". For the sake of sustainability, it is desirable to develop alternative catalysts based on metal-free resources [33]. In this review, we focus on the cycloaddition of $\mathrm{CO}_{2}$ to epoxides using metal-free catalysts, including organic bases, ILs, supported catalysts, organic copolymers and carbon materials. Recent advances in the design of metal-free catalysts as well as the related reaction mechanism are discussed. The synergistic effects are described in detail at the molecular level. The cooperative effects including those of hydrogen bond donors (HBDs) and organic bases, organic bases and nucleophilic anions, HBDs and nucleophilic anions as well as that of active components and supports are highlighted. The multi-functional approach and density functional theory (DFT) calculations are recommended for the design of efficient catalysts of this kind.

\section{Homogeneous metal-free catalysts}

\subsection{Organic bases}

It is generally accepted that the adsorption and activation of $\mathrm{CO}_{2}$ is important for the cycloaddition reaction. As described in previous reports, nucleophilic organic bases such as amines [34], N-heterocyclic carbenes (NHCs) [35], 1,5,7-triazabicyclo[4.4.0]dec-5-enium (TBD) [36], 1,8-Diazabicyclo[5.4.0] undec-7-ene (DBU) [37], guanidines [38] and pyridines [39] are efficient for the adsorption and activation of $\mathrm{CO}_{2}$. The organic bases used as catalyst are listed in Table 1 . Amines with an unsaturation close to the $\mathrm{N}$ atom are higher in activity than the primary nonconjugated amines, and the presence of the " $\mathrm{C}=\mathrm{N}-\mathrm{C}$ " structure is favorable for cycloaddition.

\subsubsection{Halogen-free catalysts based on organic bases}

Being superbasic in nature, NHCs act as nucleophiles to activate $\mathrm{CO}_{2}$ and form the corresponding imidazolium carboxylates $\left(\mathrm{NHC}-\mathrm{CO}_{2}\right)$, which subsequently release $\mathrm{CO}_{2}$ to react with epoxides and afford cyclic carbonates along with the release of NHCs. However, free NHCs are generally unstable as a result of being air- and moisture-sensitive. Zhou et al. [40] investigated the thermal stability of 1,3-bis(2,6-diisopropylphenyl)imidazolium-2-carboxylate $\left(\mathrm{IPr}-\mathrm{CO}_{2}\right)$ by in situ monitoring of the $v\left(\mathrm{CO}_{2}\right)$ region of the infrared spectrum. They found that most of the IPr- $\mathrm{CO}_{2}$ decomposed within $1 \mathrm{~h}$ at 100 ${ }^{\circ} \mathrm{C}$. Interestingly, excess $\mathrm{CO}_{2}$ was beneficial for the formation of NHC- $\mathrm{CO}_{2}$ adducts while the presence of propylene oxide (PO) accelerated the decomposition of $\mathrm{NHC}-\mathrm{CO}_{2}$ adducts and simultaneously yielded propylene carbonate (PC). In the case of

Table 1

Catalytic performance of various homogeneous organic base catalysts for cycloaddition of $\mathrm{CO}_{2}$ to epoxides.

\begin{tabular}{|c|c|c|c|c|c|c|c|}
\hline Catalyst & Epoxide & Co-catalyst or solvent & Temperature $\left({ }^{\circ} \mathrm{C}\right)$ & Pressure (MPa) & Time (h) & Yield $^{\text {a }}(\%)$ & $\mathrm{TOF}^{\mathrm{b}}\left(\mathrm{h}^{-1}\right)$ \\
\hline $\mathrm{IPr}-\mathrm{CO}_{2}[40]$ & SO & $\mathrm{C}_{2} \mathrm{H}_{2} \mathrm{Cl}_{2}$ & 120 & 2 & 24 & $97.0^{\mathrm{c}}$ & 8.1 \\
\hline $\mathrm{IBu}-\mathrm{CO}_{2}[35]$ & SO & - & 100 & 4.5 & 24 & 89.0 & 0.7 \\
\hline $\mathrm{NHO}-\mathrm{CO}_{2}[43]$ & SO & - & 120 & 2 & 24 & 82.0 & 3.4 \\
\hline $\mathrm{Bu}_{4} \mathrm{~N}^{+} \mathrm{OH}^{-}[17]$ & SO & - & 120 & 1 & 24 & 88.0 & 3.7 \\
\hline DBU [46] & PO & - & 120 & 2 & 2 & $79.2^{c}$ & 3.8 \\
\hline DMAP [47] & PO & - & 120 & 1.2 & 3 & 30.7 & 8.5 \\
\hline DMAP [45] & PO & $p-\mathrm{MeOC}_{6} \mathrm{H}_{4} \mathrm{OH}$ & 120 & 3.57 & 48 & 98.0 & 5.1 \\
\hline DBU [46] & PO & Cellulose & 120 & 2 & 2 & $92.0^{c}$ & 4.4 \\
\hline DBU [46] & PO & $\mathrm{H}_{2} \mathrm{O}$ & 120 & 2 & 2 & 45.4 & 2.2 \\
\hline DMAP [47] & PO & $\mathrm{H}_{2} \mathrm{O}$ & 120 & 1.2 & 3 & $97.0^{c}$ & 26.9 \\
\hline 2-Py-EtOH [39] & PO & TBAI & 25 & 0.1 & 20 & 86.0 & 0.5 \\
\hline DMF [49] & PO & $\mathrm{PhCH}_{2} \mathrm{Br}$ & 120 & 1 & 24 & $75.0^{\mathrm{c}}$ & 0.6 \\
\hline DBU [50] & PO & $\mathrm{PhCH}_{2} \mathrm{Br}$ & 45 & 1 & 22 & 82.0 & 0.7 \\
\hline [HDBU]Cl [51] & PO & - & 140 & 1 & 2 & 97.0 & 48.5 \\
\hline [HTBD]Br [52] & SO & - & 80 & 8 & 20 & 88.0 & 4.4 \\
\hline
\end{tabular}

${ }^{\mathrm{a}}$ Isolated yield. ${ }^{\mathrm{b}} \mathrm{TOF}=$ molar of synthesized PC or SC over per molar catalyst per hour. ${ }^{\mathrm{c}}$ Yield determined by ${ }^{1} \mathrm{H}$ NMR spectroscopy. 
IPr- $\mathrm{CO}_{2}$, there was nearly $100 \%$ yield of $\mathrm{PC}$ at $120^{\circ} \mathrm{C}$ and $2 \mathrm{MPa}$ for $24 \mathrm{~h}$. However, the solvent $\mathrm{CH}_{2} \mathrm{Cl}_{2}$ was needed to afford high activity over the NHC-CO 2 adduct. Kayaki et al. [35] used ditert-butyl instead of 2,6-diisopropylphenyl, and applied the resulting 1,3-ditert-butylimidazolium-2-carboxylate $\left(\mathrm{IBu}-\mathrm{CO}_{2}\right)$ for the cycloaddition of $\mathrm{CO}_{2}$ and epoxides without the need of a solvent at a relatively low temperature $\left(100^{\circ} \mathrm{C}\right)$. They obtained the corresponding carbonates in yields ranging from $71 \%$ to $89 \%$ with almost $100 \%$ selectivity. The theoretical study by the DFT method suggested that the real catalyst for the cycloaddition was free NHCs rather than $\mathrm{NHC}^{-\mathrm{CO}_{2}}$ [41]. $\mathrm{N}-$ Heterocyclic olefin (NHO) with high electronegativity at the terminal carbon atom was found to show a strong tendency for $\mathrm{CO}_{2}$ sequestration, affording a $\mathrm{CO}_{2}$ adduct $\left(\mathrm{NHO}-\mathrm{CO}_{2}\right)$ with a $\mathrm{C}_{\text {carboxylate }}-\mathrm{C}_{\mathrm{NHO}}$ bond longer than the $\mathrm{C}_{\text {carboxylate }}-\mathrm{C}_{\mathrm{NHC}}$ bond of NHC $[42,43]$. Various $\mathrm{CO}_{2}$, COS and $\mathrm{CS}_{2}$ adducts of NHO using $N, N$-disubstituted derivatives of 2-methyl imidazolium iodide were also reported. Among these, the $\mathrm{NHO}-\mathrm{CO}_{2}$ adducts were found to be more active ( $\mathrm{TOF}=3.4 \mathrm{~h}^{-1}$ ), while the $\mathrm{NHO}-\mathrm{CS}_{2}$ adducts exhibited the lowest activity for the cycloaddition of $\mathrm{CO}_{2}$ to epoxides. The poor activity of the NHO-CS 2 adducts was due to difficulty in releasing the highly active $\mathrm{NHO}$ as a result of the shorter $\mathrm{C}_{\mathrm{CS} 2}-\mathrm{C}_{\mathrm{NHO}}$ bond. The mechanism over the $\mathrm{NHO}-\mathrm{CO}_{2}$ adducts for the cycloaddition reaction was proposed as: (i) free $\mathrm{NHO}$ is released when $\mathrm{NHO}-\mathrm{CO}_{2}$ is heated; (ii) nucleophilic attack of the less hindered carbon atom of epoxide by NHO results in the generation of an alkoxy anion; (iii) nucleophilic attack of the carbon atom in carbonyl group by the alkoxy anion produces cyclic carbonate by intramolecular cyclic elimination, and release of $\mathrm{NHO}$; and (iv) $\mathrm{NHO}$ reacts with excess $\mathrm{CO}_{2}$ to regenerate the $\mathrm{NHO}-\mathrm{CO}_{2}$ adduct (Fig. 1) [43].

Owing to its strong basicity, quaternary ammonium hydroxide is used as $\mathrm{CO}_{2}$ adsorbent as well as catalyst for the cycloaddition reaction $[17,44]$. With $\mathrm{Bu}_{4} \mathrm{~N}^{+} \mathrm{OH}^{-}$as catalyst, $88 \%$ yield of styrene carbonate (SC) was achieved at $120{ }^{\circ} \mathrm{C}$ and 1 MPa after $24 \mathrm{~h}$. In addition to DFT calculations, a D-labeled epoxide and an optically active epoxide were used to study the reaction mechanism over quaternary ammonium hydroxide. The bicarbonate ion of tetrabutylammonium bicarbonate was

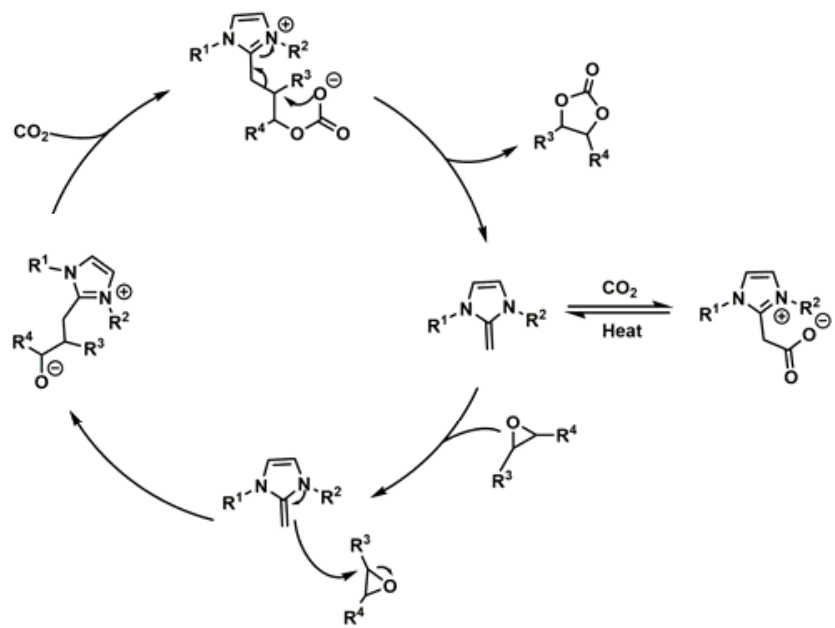

Fig. 1. Mechanism for the reaction of $\mathrm{CO}_{2}$ with epoxides catalyzed by $\mathrm{NHO}-\mathrm{CO}_{2}$ adduct [43]. recognized as the catalytically active species that attacks the less hindered $\mathrm{C}$ atom of the epoxide to generate a ring-opened alkoxide intermediate. The insertion of $\mathrm{CO}_{2}$ into the alkoxide intermediate forms a carbonate ion which cyclizes to form the cyclic carbonate [17].

It was reported that there is a positive synergetic effect between the HBDs and Lewis base in the cycloaddition reaction [45-47]. Several typical organic bases such as DBU, $\mathrm{N}, \mathrm{N}$ dimethylaminopyridine (DMAP), 1,4-diazabicyclo[2.2.2] octane (DABCO), triethanolamine (TEOA), diethanolamine (DEOA), monoethanolamine (MEOA), imidazole (Im), pyridine (Py), triethylamine (TEA), and diethylamine (DEA). and HBDs such as cellulose, chitosan, poly(ethylene glycol)-600 (PEG600), poly(ethylene glycol)-400 (PEG400), glycerine, $\beta$-cyclodextrin ( $\beta$-CD), $\mathrm{H}_{2} \mathrm{O}$ and 1,2-propylene glycol (PG) were explored to investigate the synergetic effects of bases and HBDs on the synthesis of cyclic carbonates. The activity order of the above bases was not strictly according to the established pKa order: $\mathrm{DBU}>\mathrm{DMAP}>\mathrm{DABCO} \approx \mathrm{TEOA}>\mathrm{DEOA} \approx \mathrm{MIm}>\mathrm{MEOA}>\mathrm{TEA}>$ $\mathrm{DEA} \approx \mathrm{Py}>\mathrm{Im}$, indicating that the basicity of the bases is influential for the cycloaddition reaction. The high activity of DBU may be due to its nucleophilic ability as well as its $\mathrm{CO}_{2}$ adsorption and activation ability. Moreover, a catalytic activity order of TEOA $>$ DEOA $>$ MEOA $>$ TEA $>$ DEA indicated that the presence of hydroxyl group is also important. Further study showed that the corresponding activity order for the above HBDs is cellulose $>$ chitosan $\approx$ glycerine $\approx$ PEG400 $>$ PEG600 $\approx$ $\beta$-CD $>\mathrm{H}_{2} \mathrm{O}$. A plausible mechanism is that nucleophilic attack of DBU on the epoxide coordinated with cellulose through hydrogen bonding results in opening the epoxy ring, and then the reaction with the $\mathrm{CO}_{2}$ activated by $\mathrm{DBU}$ gives the corresponding cyclic carbonate (Fig. 2) [46]. Different from the disadvantage of $\mathrm{H}_{2} \mathrm{O}$ for the catalytic activity of DBU in the report of Sun et al. [46], Roshan et al. found that the presence of a catalytic amount of $\mathrm{H}_{2} \mathrm{O}$ was advantageous for the synthesis of PC over common organic bases such as Im, Py and DMAP, giving over $98 \%$ product selectivity $\left(120{ }^{\circ} \mathrm{C}, 1.2 \mathrm{MPa}, 3 \mathrm{~h}\right)$. According to the DFT investigation, the carboxylate end of the bicarbonate moiety generated in the water- $\mathrm{CO}_{2}$-base reaction,

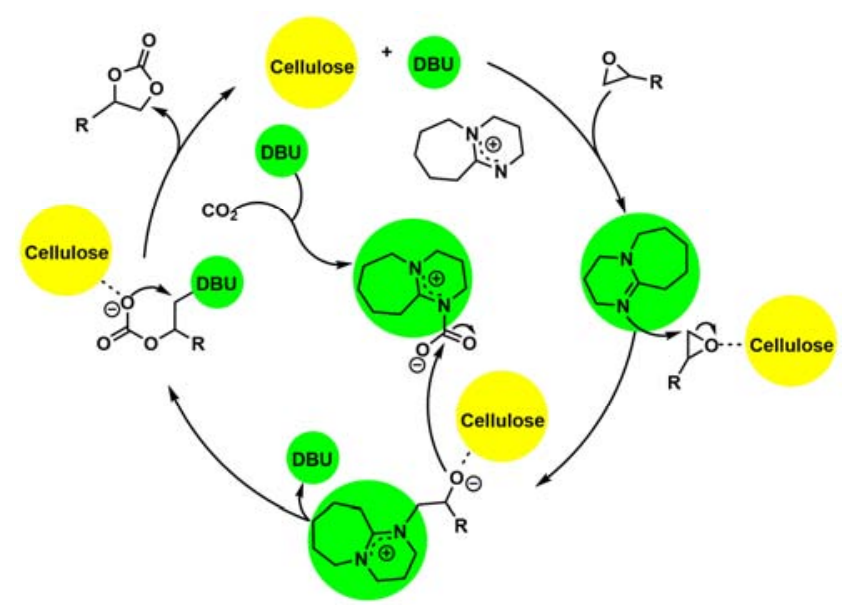

Fig. 2. Mechanism for the cycloaddition reaction catalyzed by DBU/ cellulose [46]. 
rather than the carbamate salt or hydroxyl group, was the key active species that gave the higher activity of the base-water systems [47].

With the synergetic effect of HBDs and Lewis base recognized, organic bases functionalized with a hydroxyl group such as 2-pyridinemethanol (2-Py-EtOH) and 2,6pyridinedimethanol were developed for high efficiency $\mathrm{CO}_{2}$ and epichlorohydrin (ECH) cycloaddition under mild conditions $\left(T=25-60{ }^{\circ} \mathrm{C}, 0.1 \mathrm{MPa}\right.$ of $\mathrm{CO}_{2}$ ). It was observed that there was no catalytic activity over benzyl alcohol. When pyridine was used as catalyst, the yield of cyclic carbonate was low (39\%, 60 ${ }^{\circ} \mathrm{C}$ ). In the case of 2-Py-EtOH, the yield of cyclic carbonate was $75 \%\left(60^{\circ} \mathrm{C}\right)$. The results indicate that both the basic and the hydroxyl group of 2-Py-EtOH are essential for the promotion of reaction. The ${ }^{1} \mathrm{H}$ NMR spectra of 2-Py-EtOH with and without ECH showed a clear upfield shift of OH proton signal (from $\delta=$ 6.50 to $5.49 \mathrm{ppm}$ ), indicating the presence of hydrogen bonding between ECH and pyridinemethanol [39]. It was recognized that the one-component substrates containing HBDs $(-\mathrm{OH}$ and $-\mathrm{COOH}$ ) and Lewis basic sites (pyridinic $\mathrm{N}$ and $\mathrm{N}-\mathrm{C}=\mathrm{N}$ structure) are potential metal- and halide-free catalysts for the cycloaddition reaction.

\subsubsection{Halide-containing organic base catalytic systems}

\subsubsection{Binary catalysts containing organic base and halide}

Organic bases are excellent adsorbents for $\mathrm{CO}_{2}$ capture as well as solvents [13]. Using DMF as solvent, Nbromosuccinimide (NBS) as catalyst and benzoyl peroxide (BPO) as co-catalyst, Kozak and coworkers [48] developed a new method for the continuous synthesis of cyclic carbonates from $\mathrm{CO}_{2}$ and epoxides. With a residence time of $30 \mathrm{~min}$, the system was operated at steady state for $14 \mathrm{~h}$, and $82 \%$ isolated yield of cyclic carbonate was achieved ( $5 \mathrm{~mol} \% \mathrm{NBS}$ and BPO, 2 mol/L 1,2-epoxyoctane in DMF, $120{ }^{\circ} \mathrm{C}, 0.7 \mathrm{MPa}$ ). A series of kinetics experiments confirmed the participation of DMF as well as the activation of epoxides by electrophilic bromine (rather than $\mathrm{Br}^{-}$). A mechanism was proposed: (i) $\mathrm{Br}_{2}$ is generated in situ by the reaction of NBS with DMF, (ii) $\mathrm{Br}_{2}$ reacts with epoxides to form bromo-oxonium species while $\mathrm{CO}_{2}$ is activated over DMF, (iii) the bromo-oxonium species are activated by the activated $\mathrm{CO}_{2}$ nucleophile, and (iv) after the opening of the epoxide ring, the cleavage of $\mathrm{O}-\mathrm{Br}$ bond is induced by $\mathrm{Br}^{-}$, regenerating $\mathrm{Br}_{2}$ and liberating the alkoxide anion that undergoes cyclization to generate the cyclic carbonate (Fig. 3).

Using benzyl halides and amides (DMF, DMAc, N-formylmorpholine, $\mathrm{N}$-methylpyrrolidone, and $\mathrm{N}$-formylpiperidine) as catalyst sources, Wang and coworkers [49] conducted the cycloaddition of epoxides with ambient $\mathrm{CO}_{2}$ following an easy and mild procedure to afford five-membered cyclic carbonates in moderate-to-high yields (47\%-86\%). They reported that DMF was the best ( $86 \%$ yield) among the amides. The $\mathrm{BnBr}$ was activated by DMF, and the benzyl cation generated was identified by ${ }^{1} \mathrm{H}$ NMR analysis. The authors attributed the excellent activity to the electrophilic activation of epoxides by benzyl cations and the nucleophilic activation of $\mathrm{CO}_{2}$ by DMF (a)

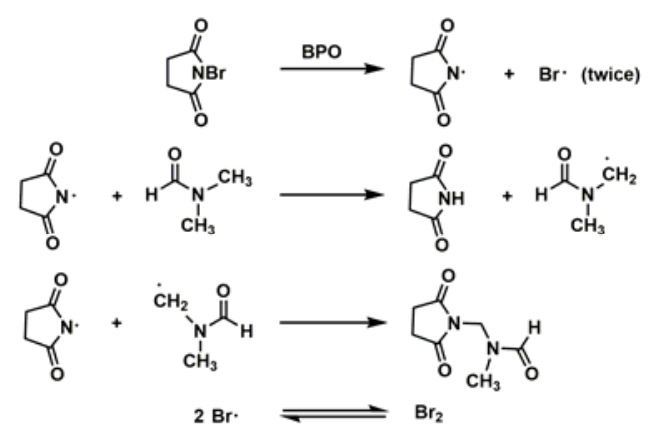

(b)

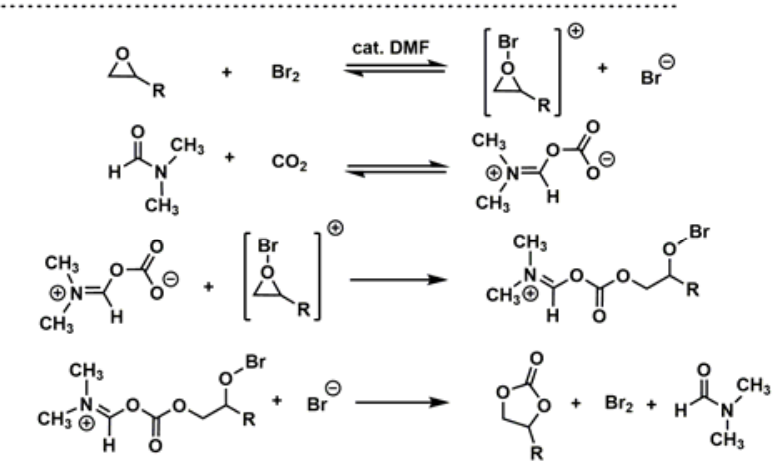

Fig. 3. Mechanism for $\mathrm{CO}_{2}$ cycloaddition to epoxides catalyzed by NBS/DMF [48].

(Fig. 4). However, the activity of $\mathrm{DMF} / \mathrm{BnBr}$ for $\mathrm{CO}_{2}$ cycloaddition to styrene oxide (SO) at ambient $\mathrm{CO}_{2}$ pressure was unsatisfactory, even at $120{ }^{\circ} \mathrm{C}$ for $24 \mathrm{~h}$ [49]. The organic bases DBU, DABCO, DMAP, Py, TEA, Im and 1,5-diazabicyclo [4.3.0]non-5-ene were also combined with $\mathrm{BnBr}$ for the cycloaddition reaction under mild conditions $\left(65^{\circ} \mathrm{C}, 0.1 \mathrm{MPa}\right)$. The order of catalytic activity was largely in accordance with the order of the $\mathrm{p} K_{\mathrm{a}}$ values of the bases, except for DABCO that showed unsatisfactory activity as a result of high steric hindrance. In addition, the benzyl bromide derivatives with an electron-donating group gave better results than those with an

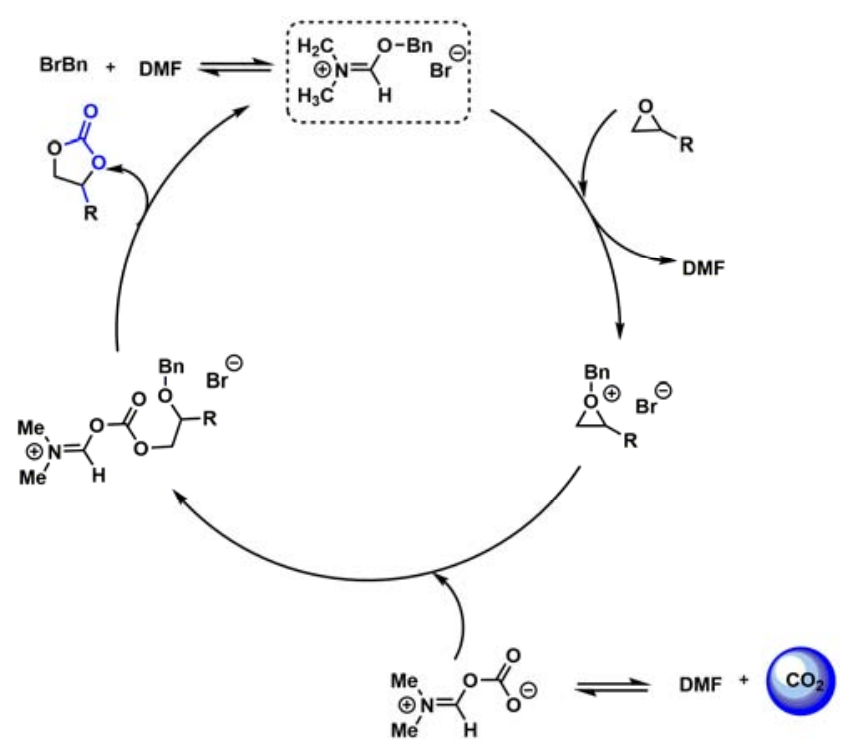

Fig. 4. Reaction pathway for the synthesis of cyclic carbonates catalyzed by BrBn/DMF [49]. 
electron-withdrawing group. In the case of the latter, there was decline of leaving of the bromide anion from the aminidinium center. Kinetic studies on the catalytic conversion of $\mathrm{CO}_{2}$ and $\mathrm{ECH}$ to cyclic carbonate over $\mathrm{DBU} / \mathrm{BnBr}$ indicated the participation of the $\left(\mathrm{Bn}-\mathrm{DBU}^{+} \mathrm{Br}^{-}\right)$complex that was initially formed from $\mathrm{DBU}$ and $\mathrm{BnBr}$ in the catalytic cycle, similar to that of the $\mathrm{DMF} / \mathrm{BnBr}$ binary catalytic system. In other words, the opening of the epoxide ring involves the nucleophilic attack from the $\mathrm{Br}^{-}$of $\mathrm{Bn}-\mathrm{DBU}^{+} \mathrm{Br}^{-}$rather than from $\mathrm{BnBr}$ [50].

The above results demonstrated the synergetic effect between the nucleophilic anion and Lewis base as well as that between HBDs and Lewis base for the enhancement of the cycloaddition reaction. Recently, Wang et al. [39] developed a $\mathrm{Bu}_{4} \mathrm{NX}(\mathrm{X}=\mathrm{Cl}, \mathrm{Br}, \mathrm{I})$ and hydroxyl group functionalized $\mathrm{Py}$ (2-Py-EtOH and 2,6-pyridinedimethanol) binary system for the cycloaddition of $\mathrm{CO}_{2}$ to epoxides at room temperature and atmospheric pressure. The catalysts are efficient and the system is metal-free and solvent-free. In the case of $\mathrm{Bu}_{4} \mathrm{NI} / 2-\mathrm{Py}-\mathrm{EtOH}$, the yields of the corresponding carbonates ranged from $65 \%$ to $97 \%\left(25^{\circ} \mathrm{C}, 0.1 \mathrm{MPa}, 20 \mathrm{~h}\right)$. The excellent performance was attributed to the synergetic effect of the hydroxyl group and halide anion for epoxide ring opening as well as to the basic sites for $\mathrm{CO}_{2}$ adsorption and activation.

\subsubsection{Organic base salts}

Salts derived from organic bases were used as one-component catalysts for the cycloaddition reaction. From DABCO, DBU, TBD and hexamethylene-tetramine (Hatm), hydrochloride salts were generated and tested [51]. Consistent with the report of $\mathrm{Yu}$ et al. [34], the presence of the "N=C-N" entity in the cation favored the cycloaddition. Among the TBD $\cdot \mathrm{HX}\left(\mathrm{X}=\mathrm{Cl}, \mathrm{Br}, \mathrm{OAc}, \mathrm{C}_{2} \mathrm{~F}_{3} \mathrm{O}_{2}\right)$ salts, TBD $\mathrm{HBr}$ displayed the best SC yield (88\%). The kinetics of the reaction over TBD. $\mathrm{HBr}$ and $\mathrm{TBABr}$ were monitored by in situ FTIR and Raman spectroscopy, and TBD-HBr was found to be more efficient than TBABr. The DFT calculations on the PO-TBD·HBr complex formed from $\mathrm{TBD} \cdot \mathrm{HBr}$ and $\mathrm{PO}$ indicated that the interaction between the $\mathrm{N}-\mathrm{H}$ group of $\mathrm{TBDH}^{+}$and the oxygen of $\mathrm{PO}$ promotes the ring opening of PO [52]. Further DFT study proved that the ring opening of the epoxides before the addition of $\mathrm{CO}_{2}$ is the rate determining step [53]. The carboxyl-functionalized organic base salts were prepared by the reaction of amino acid and HI in water by a microwaveassisted one-pot procedure. The catalysts with an amino group were found to be the most efficient among the various carboxyl-functionalized organic base salts tested. Its performance can be attributed to the role of amine for $\mathrm{CO}_{2}$ adsorption and activation as well as the synergetic effect of - $\mathrm{COOH}$ and the halide anion for epoxide ring opening [54].

The results discussed so far indicate that the multisynergetic effects of HBDs and halide anions for ring opening of epoxide as well as the basic sites for adsorption and activation of $\mathrm{CO}_{2}$ are essential for $\mathrm{CO}_{2}$ cycloaddition to epoxides. It is hence desirable to develop one-component catalysts based on the concept of multi-synergetic effects.

\subsection{Ionic liquids}

ILs have attracted much attention for their unique nature such as being environment-benign, highly stable, non-volatile and non-flammable $[55,56]$. ILs can be employed as a solvent as well as a catalyst in cycloaddition reactions. Their studies were recently reviewed $[26,27,57,58]$. In the report of Yang et al. [58], task-specific ILs such as amino-functionalized ILs and superbase-derived protic ILs for $\mathrm{CO}_{2}$ capture and utilization were systematically illustrated. Fiorani et al. [26] described ILs ranging from simple "onium" species to supported IL catalysts up to 2014, including those that contained metal for $\mathrm{CO}_{2}$ cycloaddition to epoxides. For industrialization, $\mathrm{Xu}$ et al. [27] presented a broad overview of numerous catalysts with the structures and compositions depicted at atomic and molecular levels, the reactor at the unit level, and the process integration at the system level. In this section, we focus mainly on the synergistic effects with the use of ILs from 2014 up to now.

\subsubsection{Onium salts}

Industrially, quaternary ammonium salts such as TBAB are commonly used for the synthesis of cyclic carbonates from $\mathrm{CO}_{2}$ and epoxides [59]. However, the activity is low even when a massive amount of solvent is used. There were attempts to enhance the activity of the onium salts such as through the combined use of other catalysts or through modification of known catalysts with special functional groups [60-64].

\subsubsection{Quaternary ammonium salts}

Bowl-shaped tetraphosphonate cavitands are well recognized as efficient receptors for cationic species. Based on the concept of host-guest chemistry, Mirabaud et al. [60] improved catalytic reactivity of quaternary ammonium salts by combining tetraalkyl-ammonium halides (guest) with tetraphosphonate cavitand (host) (Fig. 5). The affinity of the host for the ammonium cation was demonstrated by NMR titration experiments. The strength of the ammonium/halide binding in such host-guest architecture resulted in a dramatic effect on the cleavage of ion pair and consequently the catalytic activity. The $\mathrm{Me}_{4} \mathrm{~N}^{+} \mathrm{I}^{-} @ 2 \mathrm{~b}$ binary system showed the best performance in accord with the good leaving ability and high nucleophilicity of I- ions, achieving 92\% product yield after $24 \mathrm{~h}$ and complete conversion of SO after $48 \mathrm{~h}$.

After knowing of the synergistic effect of HBDs and nucleophiles, other entities with hydroxyl groups such as silanediols, phenols, pentaerythritol (PETT) and tannic acid
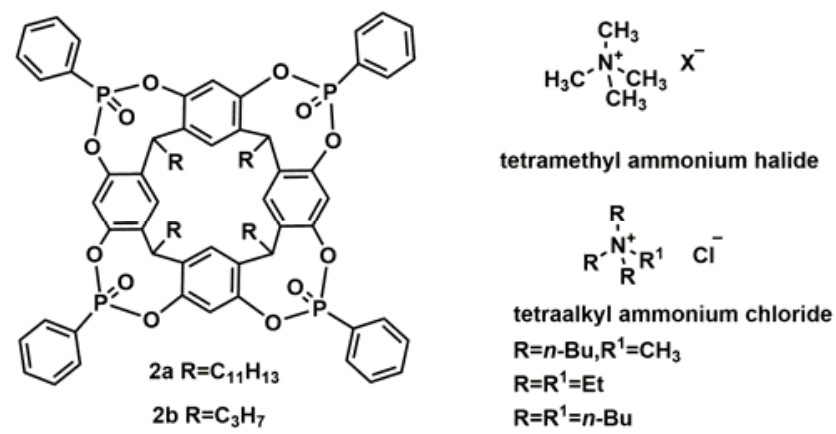

Fig. 5. Structure of tetraalkyl-ammonium halides and tetraphosphonate cavitand [60]. 
(TA) were applied to enhance the activity of onium salts. Silanediols were found to be effective $\mathrm{HBDs}$ for $\mathrm{CO}_{2}$ /epoxide coupling at room temperature and atmospheric pressure. In the presence of tetrabutylammonium iodide and SO, there was a downfield shift of the silanediol $\mathrm{O}-\mathrm{H}$ chemical signal. The phenomenon was attributed to silanediol recognition of both the epoxide and iodide through hydrogen bonding interaction. A mechanism was proposed: (i) the coordination of epoxide with silanediol through hydrogen bonding forms complex I; (ii) the activated epoxide undergoes ring opening upon nucleophilic attack of $\mathrm{I}^{-}$and yields alkoxide II that is stabilized by hydrogen bonding with silanediol; (iii) the addition of $\mathrm{CO}_{2}$ to II generates silanediol-stabilized intermediate III; (iv) cyclic carbonate is formed through an intramolecular cyclic step, together with the release of $\mathrm{I}^{-}$and silanediol (Fig. 6) [61]. Alves et al. [62] developed a catalytic platform based on an onium salt/phenols binary system efficient for the cycloaddition reaction under mild conditions $\left(60{ }^{\circ} \mathrm{C}\right.$ and $\left.2 \mathrm{MPa}\right)$, and found that multi-phenolic compounds were more efficient than phenol. Using online IR spectroscopy, kinetic studies were conducted and the commercially available HBDs (pyrogallol, pyrocatechol, gallic acid, perfluoro-tert-butanol, hexafluoro(p-tolyl)-isopropanol and 1,3-bis-(2-hydroxyhexafluoroisopropyl)-benzene) were identified as efficient co-catalysts. A multi-hydroxyl approach was also reported by Wilhelm et al. [63]. There was no or little conversion of PO over PETT or nBu4NI whereas $96 \%$ yield of PC was afforded over $5 \mathrm{~mol} \%$ $\mathrm{PETT} / \mathrm{Bu} 4 \mathrm{NI}$ under mild conditions $\left(70{ }^{\circ} \mathrm{C}, 0.4 \mathrm{MPa}, 22 \mathrm{~h}\right)$. Sopeña et al. [64] reported a TA/NBu4X $(X=B r, I)$ binary catalyst system that was highly efficient for the cycloaddition of $\mathrm{CO}_{2}$ toward oxiranes. It was reported that the corresponding cyclic carbonates were efficiently generated even at low catalyst loading. In the case of 1,2-epoxyhexane, $86 \%$ yield of cyclic carbonate was obtained with $0.05 \mathrm{~mol} \% \mathrm{TA}$ and 0.5 mol\% Bu $4 \mathrm{NI}$ under mild condition $\left(80^{\circ} \mathrm{C}, 1 \mathrm{MPa}, 24 \mathrm{~h}\right)$.

The carboxyl group is generally considered a stronger HBD than the hydroxyl group. Composed of carboxyl-containing HBDs (EDTA or EDTA-3Na) and quaternary ammonium salts (TBAB or TBAI), the binary catalyst system was efficient for the

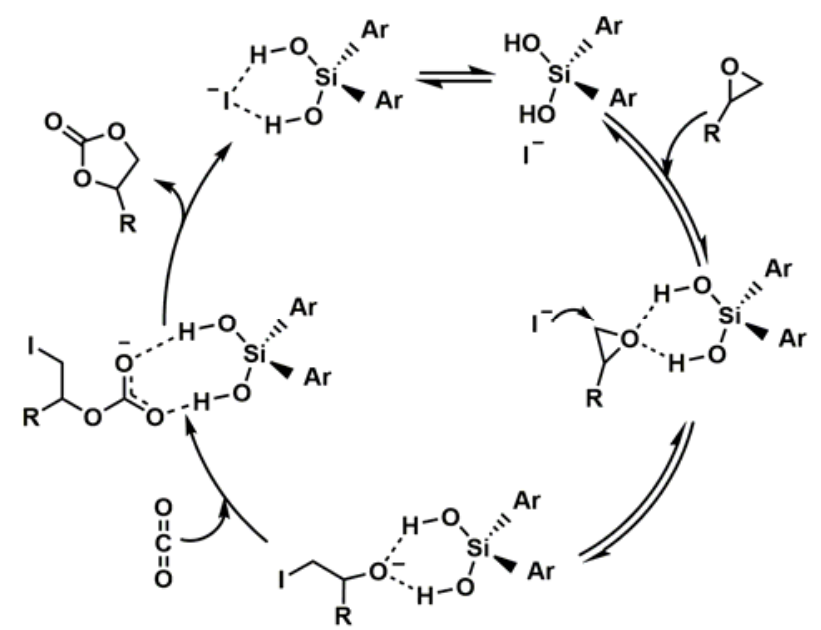

Fig. 6. Reaction pathway for the formation of cyclic carbonates over TBAI/Silanediols [61]. synthesis of cyclic carbonates from $\mathrm{CO}_{2}$ and epoxides, giving excellent yield and selectivity without the need of a solvent. When EDTA or TBAB as catalyst, the former gave no product while the latter showed a SC yield of only $58 \%$. In contrast, the combined use of EDTA and TBAB rendered a SC yield of $94 \%$ $\left(70{ }^{\circ} \mathrm{C}, 0.5 \mathrm{MPa}, 18 \mathrm{~h}\right)$. In addition, the combination of TBAB with EDTA-3Na bearing one carboxyl group gave a SC yield of only $68 \%$. When the amount of EDTA-3Na was raised to four times with equal moles of free carboxyl compared to EDTA, only 78\% SC yield was achieved. It was noted that the results were not consistent with that of Zn-EDTA complexes [65]. The results demonstrated that having multiple carboxylic groups in one molecule can have the epoxide activated more effectively, and the alkoxide intermediate is stabilized through multi-site hydrogen bonding. Moreover, intramolecular hydrogen bonding is more effective than intermolecular hydrogen bonding in terms of epoxide activation [66].

The quaternary ammonium salts functionalized with HBDs are also efficient for the cycloaddition reaction. By alkylation of tertiary amine with haloalcohols, one-component ammonium salts bearing HBDs were synthesized for the coupling of $\mathrm{CO}_{2}$ with epoxides under mild conditions $\left(45\right.$ or $90^{\circ} \mathrm{C}$ ). The bifunctional ammonium salts showed activities superior to those of the corresponding ammonium salts. The reaction could be conducted even on a multigram scale [67]. The mechanism of $\mathrm{CO}_{2}$ cycloaddition to epoxides catalyzed by 2-hydroxyl-ethyl-triethylammonium bromide (HETBAB) was investigated using the DFT method. The results suggested that the presence of an $-\mathrm{OH}$ functional group is essential for the improvement of catalytic activity [68]. Betaine-based salts (QGLY) can be considered as carboxyl functionalized quaternary ammonium salts. Park and coworkers synthesized QGLY by microwave-assisted quaternization of glycine. DFT was used to simulate the synergistic effect of - $\mathrm{COOH}$ group and halide ion of QGLY on the enhancement of catalytic activity [69].

\subsubsection{Quaternary phosphorus salts}

The phosphonium-based ILs are efficient for cycloaddition. Carbonate and carboxylate methyltrioctylphosphonium ILs were designed as halide-free and metal-free organocatalysts for $\mathrm{CO}_{2}$ cycloaddition to SO. The carboxylate and carbonate anions were active nucleophiles for SO conversion. However, as proved by the ${ }^{1} \mathrm{H},{ }^{13} \mathrm{C}$, and ${ }^{31} \mathrm{P}$ NMR analysis, the above ILs was progressively converted to phosphine oxide [70]. Werner et al. [71] prepared hydroxyl functional quaternary phosphorus salts (HQPS) by one-step reaction of phosphine and halo derivatives that contained hydroxyl group. In the case of cycloaddition reaction of 1,2-butylene oxide and $\mathrm{CO}_{2}$ at $90^{\circ} \mathrm{C}$ and $1 \mathrm{MPa}$, the yield of cyclic carbonate showed an increasing trend of $\mathrm{Bu}_{4} \mathrm{PI}<$ $\mathrm{Bu}_{4} \mathrm{PBr}<\mathrm{Bu}_{4} \mathrm{PCl}$ that matched the order of nucleophilicity. However, when $\left[\mathrm{HO}\left(\mathrm{CH}_{2}\right)_{2} \mathrm{PBu}_{3}\right] \mathrm{X}$ was employed, the order changed to $\left[\mathrm{HO}\left(\mathrm{CH}_{2}\right)_{2} \mathrm{PBu}_{3}\right] \mathrm{Cl}<\left[\mathrm{HO}_{(}\left(\mathrm{CH}_{2}\right)_{2} \mathrm{PBu}_{3}\right] \mathrm{Br}<$ $\left[\mathrm{HO}\left(\mathrm{CH}_{2}\right)_{2} \mathrm{PBu} 3\right] \mathrm{I}$ at the reaction temperature of $90{ }^{\circ} \mathrm{C}$, and changed to $\left[\mathrm{HO}\left(\mathrm{CH}_{2}\right)_{2} \mathrm{PBu}_{3}\right] \mathrm{I}<\left[\mathrm{HO}\left(\mathrm{CH}_{2}\right)_{2} \mathrm{PBu}_{3}\right] \mathrm{Cl}<$ $\left[\mathrm{HO}\left(\mathrm{CH}_{2}\right)_{2} \mathrm{PBu}_{3}\right] \mathrm{Br}$ when the cycloaddition reaction was conducted at $120^{\circ} \mathrm{C}[72]$. As previously reported, the presence 
of hydrogen bond interactions between epoxides and HBDs results in a decrease of the activation energy for epoxide ring opening [67,68]. In this case, besides nucleophilicity, the leaving ability of the halide ions is critical as well. In addition, the product yield increased with the change of substituent $\mathrm{R}$ of $\left[\mathrm{HO}\left(\mathrm{CH}_{2}\right)_{2} \mathrm{PR}_{3}\right] \mathrm{I}$ in the order of $\mathrm{Me}<\mathrm{Ph}<\mathrm{Cy}=\mathrm{Bu}=$ Oct. The phenomenon can be attributed to the increase of nucleophilicity at iodide, since the bulkiness of the cation results in weakening of the ion pair. In the case of $\left[\mathrm{HO}\left(\mathrm{CH}_{2}\right)_{2} \mathrm{PBu}_{3}\right] \mathrm{I}, 92 \%$ yield of 1,2-butylene carbonate was achieved at $90^{\circ} \mathrm{C}$ in $2 \mathrm{~h}$ [72].

In the report of Dai et al. [73], various functionalized phosphonium-based ILs were prepared and evaluated for the cycloaddition of $\mathrm{CO}_{2}$ to epoxides in the absence of co-catalyst and solvent. The strong acidity facilitated the ring opening of epoxides, and the weak electrostatic interaction enhanced the nucleophilic attack ability of $\mathrm{Br}^{-}$. In the presence of alkyl compounds that contained hydroxyl, carboxyl and amino group, there was enhancement of $\left[\mathrm{Ph}_{3} \mathrm{PC}_{2} \mathrm{H}_{4}\right] \mathrm{Br}$ activity, and $\left[\mathrm{Ph}_{3} \mathrm{PCH}_{2} \mathrm{COOH}\right] \mathrm{Br}$ showed the best performance among these functionalized catalysts. A similar phenomenon was observed in the case of pyridinium-based IL with $-\mathrm{COOH},-\mathrm{OH},-\mathrm{SO}_{3} \mathrm{H}$ and $-\mathrm{NH}_{2}$ functional groups, and only the presence of $-\mathrm{COOH}$ resulted in catalytic activity better than that of the traditional pyridinium-based IL [74]. In the case of functionalized guanidinium ILs, the order of activity enhancement was amino group > carboxyl > hydroxyl which was similar to the order of the stability of the hydrogen bond between epoxide and HBDs: carbamic acid (generated by the reaction of primary amine with $\mathrm{CO}_{2}$ ) > carboxyl > hydroxyl [75]. The above results suggested that the selection of an appropriate functional group is essential for the cycloaddition reaction.

Recently, Zhou et al. [76] developed a series of phosphorus ylide (P-ylide) $\mathrm{CO}_{2}$ adducts. The novel P-ylide $\mathrm{CO}_{2}$ adducts were efficient metal- and halogen-free catalysts that transformed $\mathrm{CO}_{2}$ into functionalized cyclic carbonates with alkyl, alkenyl, alkynyl, phenyl, halide, ether, amino and ester groups under ambient conditions $\left(25{ }^{\circ} \mathrm{C}\right.$ and $0.1 \mathrm{MPa}$ of $\left.\mathrm{CO}_{2}\right)$. The intermolecular synergistic effects of the phosphonium moiety as an onium salt and the carboxylate moiety acting as a nucleophile for activating epoxides was suggested by the kinetic study based on in situ FTIR.

\subsubsection{Imidazolium ILs}

\subsubsection{Conventional imidazolium ILs}

With tunable structure and function, imidazole ILs are widely used in cycloaddition reactions (Fig. 7) [27]. Anthofer et al. [77] controlled the activity of imidazolium-based ILs [R1 $\left.\mathrm{R}^{2} \mathrm{R}^{3} \mathrm{Im}\right] \mathrm{Br}\left(\mathrm{R}^{1}=\mathrm{H}, \mathrm{CH}_{3}\right.$, benzyl, 1-(2,3,4,5,6-pentafluoro) benzyl; $\mathrm{R}^{2}=\mathrm{H}, \mathrm{CH}_{3}, \mathrm{C}_{2} \mathrm{H}_{5} ; \mathrm{R}^{3}=n$-butyl, $n$-octyl) for the reaction of $\mathrm{CO}_{2}$ cycloaddition to $\mathrm{PO}$ by changing the substituents of the imidazole cations. The substitution of the acidic ring proton at the 2-position by methyl and ethyl groups resulted in a reduction of PO conversion. The hydrogen bond interaction between the acidic imidazolium proton and the oxygen atom of PO was shown by FT-IR analysis. This suggested that the
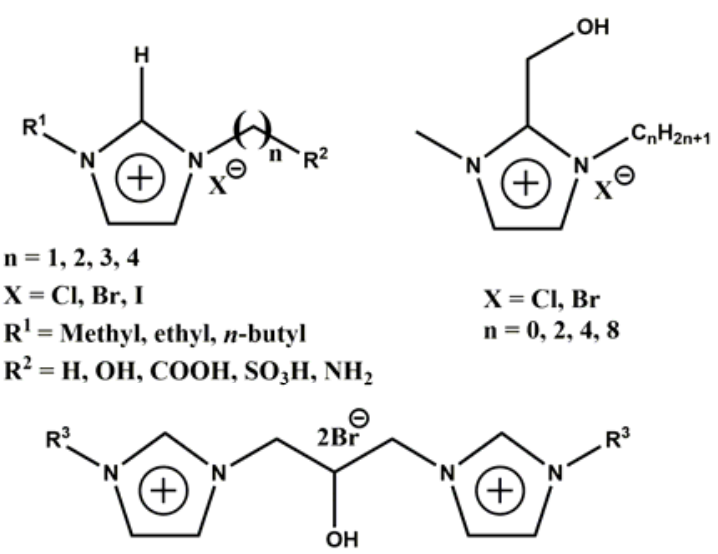

$\mathrm{R}^{3}=$ Methyl, benzyl, $n$-octyl

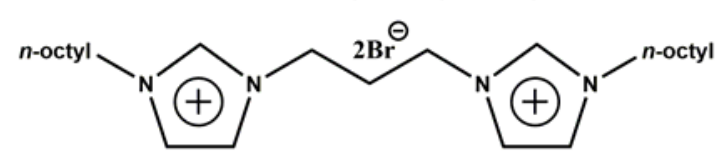

Fig. 7. Structure of functionalized imidazolium ILs.

contact between the imidazolium ring proton at the $\mathrm{C} 2$-position and the epoxide oxygen atom facilitated epoxide ring opening by nucleophilic $\mathrm{Br}^{-}$attack. The bulk steric hindrance on $\mathrm{C}_{1}$ and $\mathrm{C}_{3}$ were favorable for high catalytic activity. In the work of Girard et al. [78], the effects of cation and anion on the activity were investigated. In the case of 1- $n$-butyl-3methylimidazolium (BMIM) derivatives, high conversion and selectivity were achieved with $\mathrm{Br}^{-}$and $\mathrm{I}^{-}$, while relatively low selectivity was observed in the cases of BMIM with $\mathrm{Cl}^{-}, \mathrm{AcO}^{-}$, $\mathrm{HCO}_{3}{ }^{-}$, malonate, and proline. It was recognized that good leaving ability of the halide ion was essential for ring closure, which is an $\mathrm{SN}_{2}$-type reaction. In the case of BMIMI replaced by 1-t-butyl-3-methylimidazolium iodide, the yield (selectivity) declined from $99 \%$ (99\%) to $77 \%$ (87\%). This was explained by the stronger acidity of the $\mathrm{H}-\mathrm{C} 2$ induced by $t$-Bu at the lateral chain that benefited the generation of phenylacetaldehyde through SO isomerisation. Both the experimental and DFT results testified that the synergetic effect of acidic and basic sites as well as the suitability of hydrogen bond strength are critical for the reaction. Further DFT study of BMIMBr for $\mathrm{CO}_{2}$ cycloaddition to SO proved that the rate determining step was the ring opening of SO as a result of nucleophilic attack of $\mathrm{Br}^{-}$on the methylene $\mathrm{C}$ atom of SO, involving mainly the cation and anion from the catalyst [79].

\subsubsection{Functionalized imidazolium ILs}

Compared with conventional Im ILs, functionalized Im ILs generally showed better catalytic activity owing to the synergistic effect between the functional groups (hydroxyl, carboxyl and amino) and nucleophiles such as halide anions (Fig. 7). As described by Wang et al. [80], the process for the cycloaddition reaction between $\mathrm{CO}_{2}$ and epoxides catalyzed by 1-(2-hydroxyl-ethyl)-3-methylimidazolium (HEMIM) chloride changed from single-step to multipath compared to the non-catalyst process, and the nucleophilic attack of anion and hydrogen bonding were two critical factors for the promotion 
of reaction. In the report of Liu et al. [81], the combined use of HBDs and 1-(2-hydroxyl-ethyl)-3-butylimidazolium bromide (HEBimBr) afforded significant enhancement of activity compared to the use of $\mathrm{HEBimBr}$ alone, and with $94 \%$ PC yield the EG/HEBimBr system showed the best performance $\left(140{ }^{\circ} \mathrm{C}\right.$, $2.0 \mathrm{MPa}, 2.5 \mathrm{~h}$ ). The DFT results suggested that the ring closing step was rate determining in the case of HEBimBr while the ring opening step was rate determining in the case of EG/HEBimBr. Anthofer et al. [82] synthesized hydroxyfunctionalized mono- and bis-imidazolium bromides and found that the activity of the latter was higher than that of the former even with the equal molarity of midazolium cations. The conversion of PO over hydroxy-functionalized bis-imidazolium bromides at $70{ }^{\circ} \mathrm{C}$ and $0.4 \mathrm{MPa}$ for $16 \mathrm{~h}$ was $95 \%$. The above functional groups were located at the nitrogen of the imidazolium rings that are commonly not stable especially in the presence of a base owing to the reactive $\mathrm{C}(2)-\mathrm{H}$ of imidazolium. Zhang's group [83] designed a series of base-stable 2-hydroxymethyl-functionalized ILs by introducing a hydroxyl methyl group to the reactive $\mathrm{C}(2)-\mathrm{H}$ of imidazolium. Different from the traditional ILs, the alkyl length of the ILs cation had little influence on the catalytic activity due to the absence of $\mathrm{C}(2)-\mathrm{H}$. The performance of the 2-hydroxymethylfunctionalized ILs was much better than that of traditional ILs, and afforded a PC yield of $83 \%-92 \%\left(110^{\circ} \mathrm{C}, 1 \mathrm{MPa}, 1 \mathrm{~h}\right)$. In addition, the DFT results again confirmed that hydrogen bonding is beneficial for stabilizing the intermediates and transition states in the cycloaddition process.

It was reported that the synergetic effect of carboxyl or hydroxyl group and halides promoted the cycloaddition reaction. Xiao et al. [84] investigated the influence of acidic strength on the catalytic activity of Brönsted acidic ILs. Weak acidity favored the increase of catalytic activity owing to the fact that strong acidic ILs, such as sulfonic acid, result in strong hydrogen bonding with the epoxide that hinders the insertion of $\mathrm{CO}_{2}$. In the case of 1-(2-carboxyethyl)-3-methylimidazolium bromine (III) as catalyst, the yield of PC was $96.3 \%\left(100{ }^{\circ} \mathrm{C}, 1.5\right.$ $\mathrm{MPa}, 2 \mathrm{~h}$ ). As suggested by the DFT study by Wang et al. [85], the elongation of the alkyl chain in the cation improved the product yield, and the use of imidazole group as cation was better than that of pyridine group.

Amino-functionalized Im ILs was prepared and used as catalysts for the cycloaddition of epoxides with $\mathrm{CO}_{2}$ [86]. Compared to the carboxyl-functionalized Im ILs, the amino-functionalized Im ILs showed better catalytic activity. This was attributed to the enhancement of $\mathrm{CO}_{2}$ adsorption and activation by amine through the formation of ammonium carbamate as well as to the hydrogen bonding between the ammonium-group and epoxide. Consistent with the report of Anthofer et al. [77], a long $\mathrm{N}$-alkyl chain in aminofunctionalized Im ILs was beneficial for the enhancement of catalytic activity. Recently, Liu et al. [87] developed ILs catalysts based on urea derivatives (denoted as UDILs) with multi-secondary amine groups. The UDILs showed double molar $\mathrm{CO}_{2}$ adsorption and reversible $\mathrm{CO}_{2}$ capture ability, as well as outstanding catalytic activity for the cycloaddition of $\mathrm{CO}_{2}$ to epoxides. Based on the kinetic studies, the authors proposed a mechanism that used the activation of epoxide and $\mathrm{CO}_{2}$ by the urea-functionalized cations and the ring-opening of epoxide induced by the nucleophilic anion.

The above results indicated that the high activity of HBDs/Ils binary catalysts and functionalized ILs can be attributed to the synergistic effect of the functional group (hydroxyl, carboxyl and amino) and nucleophile such as halide anions. In addition, the multi-hydroxyl and multi-cation concepts are suitable for the design of efficient metal-free catalysts. However, it is noted that the high price of ILs and difficulty in product separation inhibit the industrialization of ILs for the production of PC.

\subsection{Other homogeneous metal-free catalysts}

With chemically reactive acidic and basic sites, $\alpha$-amino acids (AAs) are efficient for the cycloaddition of $\mathrm{CO}_{2}$ to $\mathrm{PO}$ when a proper amount of $\mathrm{H}_{2} \mathrm{O}$ is added to the reaction system. Basic Aas, such as L-arginine, L-histidine, L-lysine showed better performance than acidic AAs such as L-aspartic acid and L-glutamic acid, and L-histidine performed the best. In the case of L-histidine, increasing the amount of $\mathrm{H}_{2} \mathrm{O}$ from $1.3 \mathrm{~mol} \%$ to $13 \mathrm{~mol} \%$ resulted in a conversion increase from $64 \%$ to $90 \%$ while the selectivity declined from $96 \%$ to $91 \%$. A reaction mechanism involving the amine moiety of the L-his imidazole ring and the synergistic interplay of the $-\mathrm{OH}$ groups in $\mathrm{H}_{2} \mathrm{O}$ and the $\mathrm{COO}^{-}$end of the zwitterionic L-his was proposed [88].

As acidic counterparts of the well-known proazaphosphatrane superbases, azaphosphatranes are used as efficient catalyst ( $0.1 \mathrm{~mol} \%$ loading) for $\mathrm{CO}_{2}$ cycloaddition to epoxides at $80^{\circ} \mathrm{C}$ and atmospheric pressure. Being structurally tunable, the catalytic activity of azaphosphatranes can be modulated by changing the substituents attached to the peripheral $\mathrm{N}$-atoms. The azaphosphatrane bearing bulkier substituents such as p-methoxybenzyl and neo-pentyl exhibited relatively higher stability than those bearing methyl substituents, and the azaphosphatrane bearing p-methoxybenzyl groups showed the highest catalytic activity. The kinetic studies suggested that epoxide was activated through hydrogen bonding with $\mathrm{P}-\mathrm{H}$, and with the insertion of $\mathrm{CO}_{2}$ into the $\mathrm{P}-\mathrm{N}$ bond, there was the generation of an unusual tricyclic phosphoryl-carbamate intermediate [89]. DFT investigation revealed that intermolecular proton transfer was essential for the reaction, and the insertion of $\mathrm{CO}_{2}$ into the $\mathrm{P}-\mathrm{N}$ bond of the catalyst led to catalytic deactivation [90]. Subsequently, Chatelet et al. [91] developed an encapsulation method by self-assembly giving a nano-cage to improve the catalytic activity and stability of azaphosphatranes. It was reported that the encapsulated azaphosphatrane showed catalytic activity and stability much better than those of the non-caged counterpart.

\section{Heterogeneous catalysts}

\subsection{Immobilized catalysts}

Although homogeneous catalysts are generally efficient for 
cycloaddition, the complicated separation process is unwelcome in industrialization. The immobilization of homogeneous catalysts on suitable supports (e.g., mesoporous materials and polymers) is an efficient and simple method to afford heterogeneous catalysts. The catalysts based on carbon materials are not presented here. They are reviewed in the later section of "Carbon materials".

\subsubsection{Immobilized organic base catalysts}

As described previously, the presence of a conjugated $\mathrm{N}=\mathrm{C}-\mathrm{N}$ structure is beneficial for the cycloaddition reaction. Having a large specific surface area and being porous, together with having an abundance of hydroxyl groups, mesoporous silica materials $\left(\mathrm{SiO}_{2}, \mathrm{SBA}-15, \mathrm{MCM}-41\right)$ are excellent supports for organic bases that contain the $\mathrm{N}=\mathrm{C}-\mathrm{N}$ structure such as TBD, guanidine and NHC. The most common method to immobilize organic bases on silica is the silylanization of the silica materials with chlorine-terminal silanes followed by the nucleophilic substitution reaction of unsaturated amines [36,38].

With a high specific surface and well-ordered architecture, the hydroxyl-rich MCM-41 is a good solid support for loading homogeneous catalysts [38]. Zhou and coworkers [92] prepared NHC-functionalized MCM-41 through the silylanization of MCM-41 with 3-mercaptopropyltrimethoxysilane followed by reaction with 1,3-bis-(4-allyl-2,6diisopropylphenyl) imidazolium chloride. In situ diffuse reflectance infrared fourier transform spectroscopy was applied to investigate the reversible $\mathrm{CO}_{2}$ capture-release ability of MCM-41-NHC. It was reported that MCM-41-NHC can effectively trap $\mathrm{CO}_{2}$ at a relatively low temperature and release the adsorbed $\mathrm{CO}_{2}$ at a higher temperature. Furthermore, MCM-41-MHC- $\mathrm{CO}_{2}$ was proved to be an efficient heterogeneous catalyst for the cycloaddition of $\mathrm{CO}_{2}$ to epoxides with excellent regioselectivity under mild conditions. In the case of PO, 100\% yield of PC was obtained at $120{ }^{\circ} \mathrm{C}$ after $48 \mathrm{~h}$. Abundant with silanols, silica $\left(\mathrm{SiO}_{2}\right)$ is also used as support for heterogenizing an organic base catalyst. Adam et al. [93] grafted 3-chloropropyl silica with tetramethylguanidine and obtained spherical nanoparticles with an average size of $19.62 \mathrm{~nm}$ and a narrow pore size distribution (3.5-4.2 nm). A conversion of $92 \%$ was achieved under the optimized reaction conditions $\left(130{ }^{\circ} \mathrm{C}, 5.0 \mathrm{MPa}, 8 \mathrm{~h}\right)$, and the PC selectivity was $98 \% . \mathrm{CO}_{2}$ was adsorbed and activated at Lewis base sites to generate the carbonate species.

In another case, both mesoporous organosilica and silica were applied as supports. Prasetyanto et al. [94] incorporated T-type melamine-based triorganosilsesquioxane of large size as an organic linker in the periodic mesoporous organosilica. The resulting melamine-based organosilica possessed a wellordered p6mm hexagonal mesostructure and performed effectively in the cycloaddition of $\mathrm{CO}_{2}$ to PO. Based on the calculated geometric parameters and adsorption energy, the authors proposed that compared to the single-type amine species, the combined use of a secondary amine and tertiary amine at a particular geometric position would result in better $\mathrm{CO}_{2}$ activation.
As discussed above, the process for cycloaddition over bases is generally by the adsorption and activation of $\mathrm{CO}_{2}$ to afford a carbamate or carbamic acid species as the initial step, followed by the subsequent nucleophilic attack to epoxides. However, the nucleophilicity of the carbamate and carbamic acid species is not enough to cause epoxide activation, and the activity of the immobilized organic base catalysts is limited. It is hence necessary to develop immobilized catalysts that have high nucleophilicity.

\subsubsection{Immobilized ILs catalysts}

In recent years, various ILs were designed as catalysts or co-catalysts for cycloaddition [26,27,60-63]. Despite their efficiency, the immobilization of them is essential to synthesize cyclic carbonates by a continuous technology.

\subsubsection{Silicon-based materials supported ILs catalysts}

Silicon-based materials are also suitable supports for the immobilization of ILs and organic bases. Dai et al. immobilized 3-(2-hydroxyl-ethyl)-1-propylimidazolium bromide (HEPIMBr) onto $\mathrm{SiO}_{2}$, SBA-15 and Al-SBA-15 mesoporous molecular sieves by the chemical grafting method. SBA-15 and unsupported $\mathrm{HEMIMBr}$ displayed poor activity for $\mathrm{CO}_{2}$ cycloaddition to $\mathrm{PO}$ while the activity remarkably increased when HEMIMBr was loaded onto the silicon materials. The activity order was SBA-15-HEPIMBr > Al-SBA-15-HEPIMBr > $\mathrm{SiO}_{2}$-HEPIMBr $>$ HEMIMBr. The excellent performance of SBA-15-HEPIMBr was attributed to the synergetic effects between the active component and support as well as $-\mathrm{OH}$ and halide anions [95]. Cheng et al. [96] found that the loading of ILs with $-\mathrm{OH}$ or $-\mathrm{COOH}$ functional groups was less than that of ILs without a functional group, but the former was more efficient than the latter. Based on experimental and DFT studies, a mechanism was proposed that involves the activation of epoxide under the influence of hydrogen bonding and nucleophilic $\mathrm{Br}^{-}$attack as well as the adsorption and activation of $\mathrm{CO}_{2}$ by the tertiary nitrogen atoms of the catalyst (Fig. 8).

In the studies of Adam and coworkers [97], imidazole was immobilized on MCM-41 using 3-chloropropyltriethoxysilane as anchoring agent, and then subjected to alkylation with 1,2-dibromoethane (Fig. 9). The material obtained was designated as MCM-41-Imi/Br. According to the ion chromatography analysis, the concentration of bromide in MCM-41-Imi/Br was $0.44 \mathrm{mmol} / \mathrm{g}$. At $100{ }^{\circ} \mathrm{C}$ and $3 \mathrm{MPa}$ for $4 \mathrm{~h}$, $100 \%$ conversion and $98.8 \%$ selectivity to SC over MCM-41-Imi/Br was achieved under solvent-free condition, while there was an obvious decline of activity with the addition of a solvent such as 1,2-dichloroethane, acetonitrile, DMF and toluene. The decline of activity was attributed to the adsorption of solvent molecules on the active sites that inhabited the activation of substrates. When $\mathrm{SC}$ was heated at $100^{\circ} \mathrm{C}$ together with MCM-41-Imi/Br in the absence of $\mathrm{CO}_{2}$ for $4 \mathrm{~h}$, 2-bromo-1-phenylethanol was detected as major product by GC-MS. The result confirmed that the ring opening of epoxide took place by a nucleophilic attack of $\mathrm{Br}^{-}$at the methylene carbon of epoxide [98].

The "multilayered covalently supported" approach was 


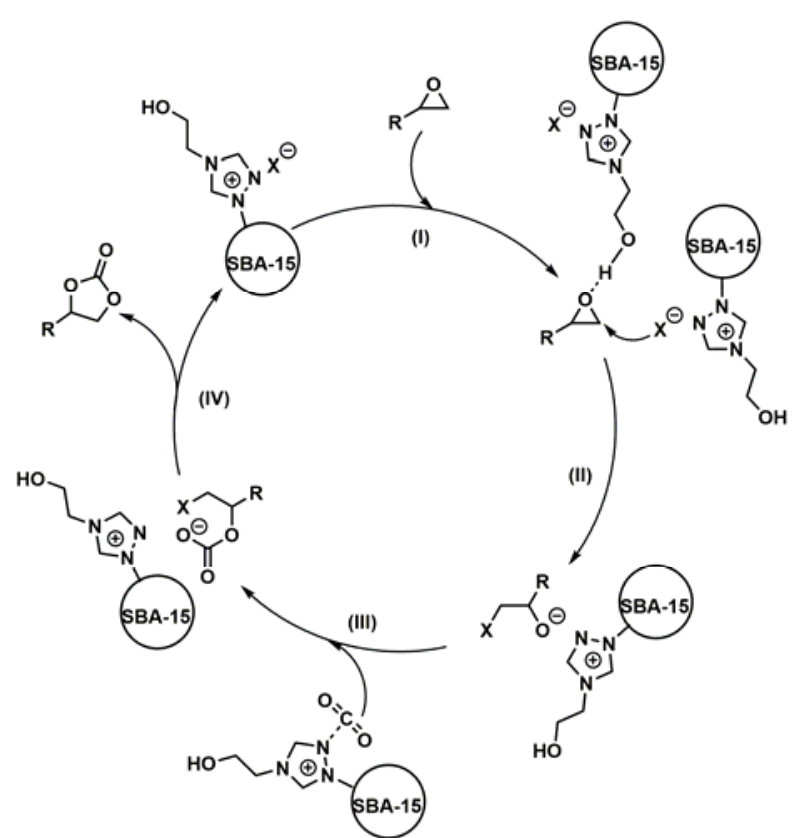

Fig. 8. Mechanism for the fixation of $\mathrm{CO}_{2}$ in the form of cyclic carbonates [96].

applied to increase the loading of ILs. Agrigento et al. [99] prepared multilayered covalently supported ILs by grafting different bis-vinylimidazolium salts on thiol-functionalized silica. The $\mathrm{SiO}_{2}$ supported bis-imidazolium iodide salt with xylene or octane as linker was identified as the most active IL-based catalyst. The superior productivity was attributed to the high IL loadings (53 wt.\% and 61 wt.\%). In addition, the "multi-hydroxyl functionalized" approach was used to generate efficient heterogeneous as well as homogeneous catalysts. Kohrt et al. [100] designed and prepared $\mathrm{SiO}_{2}$-supported triethanolammonium iodide by reacting supported amines with iodoethanol. This catalyst gave the conversion of several terminal epoxides to the corresponding cyclic carbonates in $67 \%-99 \%$ yield under mild conditions $\left(90{ }^{\circ} \mathrm{C}, 1 \mathrm{MPa}, 6 \mathrm{~h}\right)$. Compared to the triethanolammonium iodide supported on polystyrene (PS), the $\mathrm{SiO}_{2}$-supported triethanolammonium iodide gave slightly lower yields but showed much better

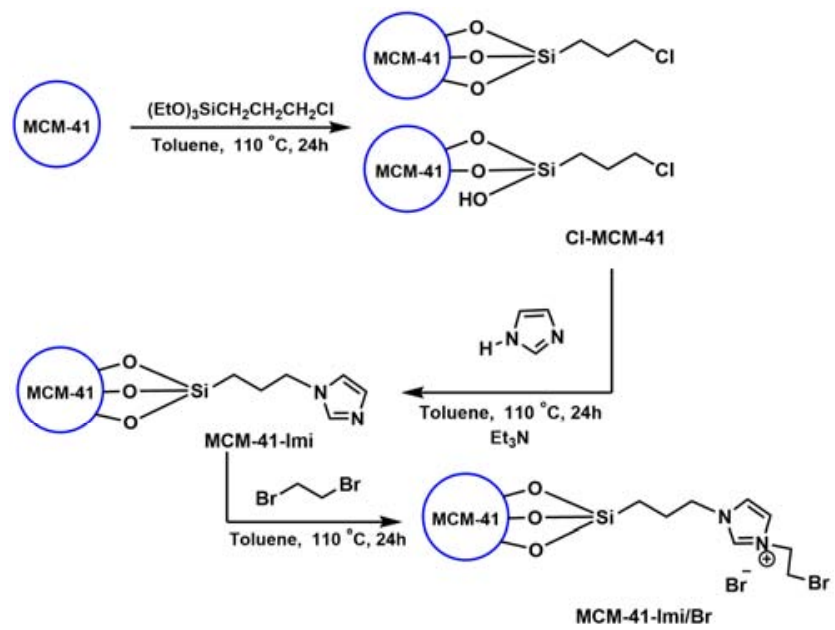

Fig. 9. Reaction sequence and the structure of MCM-41-Imi/Br [97]. stability in the reusability test. In the case of 1,2-butene oxide as substrate, $99 \%$ yield of the corresponding cyclic carbonate was achieved and the catalyst could be reused 13 times with the high activity retained.

Polyhedral oligomeric silsesquioxane functionalized with imidazolium chloride peripheries (POSS-Imi) was successfully synthesized and used for the cycloaddition of $\mathrm{CO}_{2}$ to epoxides with excellent performance. In the presence of PrOH, POSS-Imi (TON = 533) showed enhanced catalytic activity when compared to unsupported 1-butyl-3-methylimidazolium chloride (TON = 326). The excellent performance of POSS-Imi was ascribed to the synergistic effect of POSS and ILs as well as to the high concentration of imidazolium species on POSS [101].

\subsubsection{Polymer-immobilized ILs catalysts}

Being cheap, separable and easily surface-modified, organic polymers are promising candidates to support ILs and have wide applications in the synthesis of cyclic carbonates. Zhang et al. [102] developed quaternary ammonium salts functionalized polystyrene (PS) by the direct quaternarization of chloromethylated PS with $N, N$-dimethylethylamine (PS-QNS) for cycloaddition of $\mathrm{CO}_{2}$ to $\mathrm{PO}$. There was no PC produced over PS, while over QNS and PS-QNS, the PC yield was $50.7 \%$ and $7.9 \%$, respectively $\left(150{ }^{\circ} \mathrm{C}, 2 \mathrm{MPa}, 5 \mathrm{~h}\right)$. The results indicated that there is a synergistic effect between the support and catalytically active species. In the work of Deng et al. [103], the "multi-hydroxyl functionalized" approach was applied to prepare PS-supported bis-ammonium ILs based on DABCO with $-\mathrm{CH}_{2} \mathrm{COOH},-\mathrm{CH}_{2} \mathrm{CH}_{2} \mathrm{OH}$, and $-\mathrm{CH}_{2} \mathrm{CH}_{2} \mathrm{NH}_{2}$ as end groups. With the $-\mathrm{COOH},-\mathrm{OH}$, and $-\mathrm{NH}_{2}$ functional groups, there was enhanced catalytic efficiency. Saptal et al. [104] designed and developed dicationic and di-hydroxyl ILs based on DABCO for $\mathrm{CO}_{2}$ cycloaddition to PO (Fig. 10). It was reported that the [PS-DABCO-PDO][Br-Cl] catalyst performed well, giving 98\% PC yield, and can be recycled up to seven times without loss of catalytic activity $\left(100{ }^{\circ} \mathrm{C}, 2 \mathrm{MPa}, 3 \mathrm{~h}\right)$.

1,2,4-Triazolium- and Imidazole-based ILs were also covalently anchored onto PS for the cycloaddition reaction. Whiteoak et al. [105] developed PS-supported 1,2,4triazolium-based ILs containing 1,2,3-trihydroxy- benzene as catalyst for cycloaddition under mild conditions $\left(45^{\circ} \mathrm{C}\right.$ and 1 $\mathrm{MPa}$ ). The catalyst can be easily recycled and reactivated through reaction with methyl iodide. Jadhav et al. [106] found that $\mathrm{NTf}_{2}{ }^{-}$was more suitable than halide anions such as $\mathrm{Br}^{-}$and $\mathrm{Cl}^{-}$in the PS-Im catalyst system.

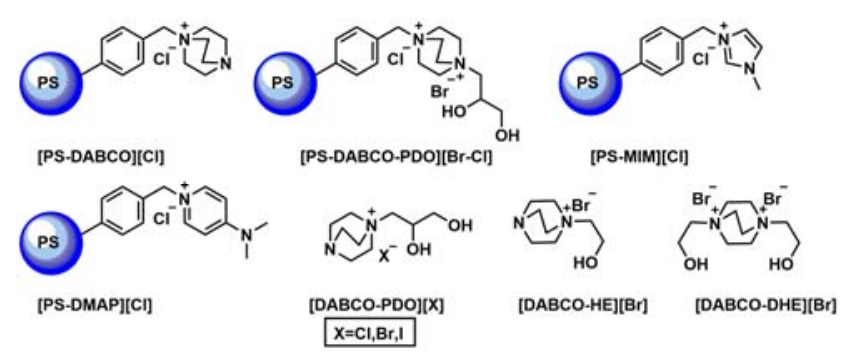

Fig. 10. Structures of functionalized and PS-supported DABCO based Ils [104]. 
A cross-linked divinylbenzene polymer (PDVB) was employed as support for the formation of heterogeneous catalysts. Dai et al. [107] developed a series of PDVB-supported ILs by reacting brominated alkanes with PDVB that was grafted with 1-(3-amino-propyl) imidazole. The catalytic activity of PDVB-ILs was in the order PDVB-HEIMBr > PDVB-AEIMBr > EtOH/PDVB-EIMBr $>$ PDVB-EIMBr, and such an order indicates the importance of hydroxyl for the cycloaddition reaction. Subsequently, a carboxyl functional group was tested and found to be good for HBDs in PDVB-Im [108]. Recently, PDVB grafted with carboxyl-, hydroxyl-, or amino-functionalized di-cation (P-FDIILs) were developed (Fig. 11). The catalyst based on the di-cation showed better performance than that based on mono-cation. The activity of PDVB-supported di-cation with different functional groups was in the order: $-\mathrm{COOH}>-\mathrm{NH}_{2}>-\mathrm{OH}$, and the $\mathrm{PC}$ yield was up to $97.8 \%$ for the $-\mathrm{COOH}$ functionalized catalyst at $130^{\circ} \mathrm{C}$ and $2.5 \mathrm{MPa}$ in $4 \mathrm{~h}$. The results suggested that the synergetic effect between the carboxyl group and halide anion facilitate the cycloaddition reaction [109].

Furthermore, FDU-type periodic polymer with a mesoporous organic framework and abundant phenolic hydroxyl was applied as support to immobilize imidazolium-based ILs (Fig. 12). In the cycloaddition of $\mathrm{CO}_{2}$ to PO, the activity of FDU-EIMBr without a hydroxyl group in the ILs was similar to those with a hydroxyl group while the homogeneous catalyst HEIMBr with a hydroxyl group showed much higher activity than EIMBr. In the case of using FDU-EIMBr as catalyst, $91 \%$ yield of PC was obtained $\left(110^{\circ} \mathrm{C}, 1\right.$ $\mathrm{MPa}, 3 \mathrm{~h}$ ). Combined with the DFT study, it is recognized that the presence of halide ions and the strong hydrogen bonding interaction between the phenolic hydroxyl group and PO are important factors that facilitate the cycloaddition reaction. In addition, the DFT study indicated that the activation of $\mathrm{CO}_{2}$ can be attributed to the tertiary ammonium of the imidazolium ring moiety [110].

\subsubsection{Biopolymer-supported ILs catalysts}

Biopolymers have the advantages of being naturally abundant, non-toxic and biocompatible as a support for homogeneous catalysts. Zhao et al. [111] were the first to develop quaternary ammonium salt functionalized chitosan (CS) for the cycloaddition of $\mathrm{CO}_{2}$ to $\mathrm{PO}$ without the need of

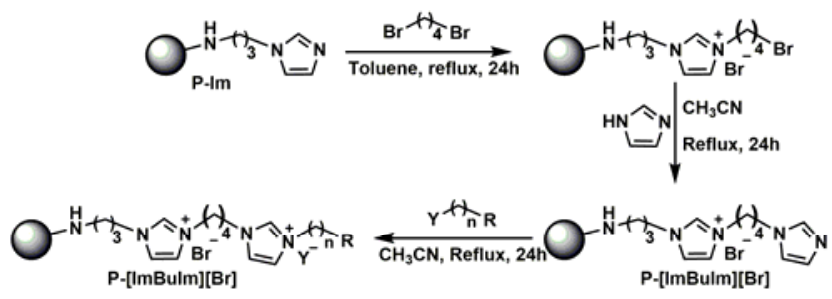

1a: $n=1, R=C O O H, Y=B r \quad 2: n=2, R=O H, Y=B r$

1b: $n=2, R=C O O H, Y=B r \quad$ 3: $n=2, R=N_{2}, Y=B r$

1c: $n=3, R=\mathrm{COOH}, Y=\mathrm{Br} \quad 4: n=2, \mathrm{R}=\mathrm{H}, Y=\mathrm{Br}$

1d: $n=4, R=C O O H, Y=B r$

1e: $n=2, R=\mathrm{COOH}, Y=\mathrm{Cl}$

1f: $n=2, R=C O O H, Y=1$

Fig. 11. Preparation of polymers grafted with functionalized DIILs [109].

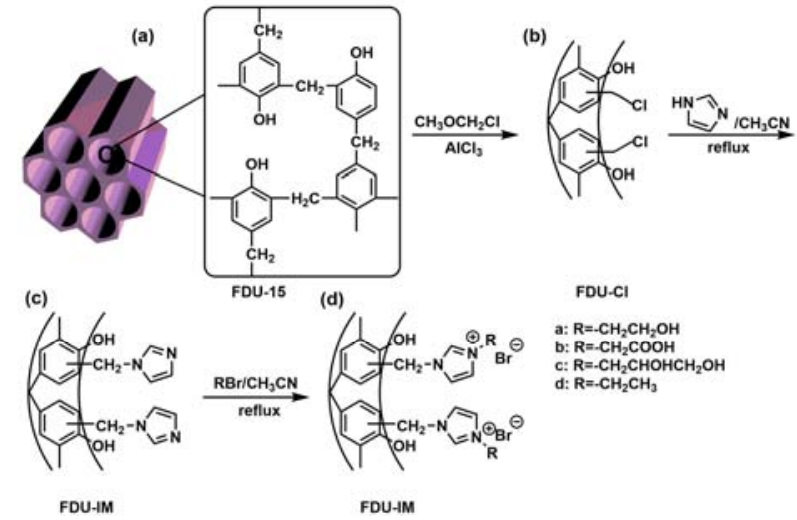

Fig. 12. Schematic for preparing a series of FDU-15 mesoporous polymer supported imidazolium-based ILs [110]. (a) FDU-HEIMBr; (b) FDU-CMIMBr; (c) FDU-DHPIMBr; (d) FDU-EIMBr.

co-catalyst and solvent. 1-Butyl-triphenylphosphoniumbromide was grafted onto CS by reacting the amine on CS with the alkyl bromide of phosphorus salt (denoted as $\left.\mathrm{CS}-\left[\mathrm{BuPh}{ }_{3} \mathrm{P}\right] \mathrm{Br}\right)$. Using $\mathrm{CS}-\left[\mathrm{BuPh}_{3} \mathrm{P}\right] \mathrm{Br}$ as catalyst, the yield of $\mathrm{PC}$ was $98.3 \%$ at $120^{\circ} \mathrm{C}$ and $2.5 \mathrm{MPa}$ in $4 \mathrm{~h}$. The ring opening of the epoxides was a combined result of polarization (caused by hydrogen bonding with the hydroxyl groups), electronic interaction (by $\left[\mathrm{BuPh}_{3} \mathrm{P}\right]^{+}$), and nucleophilic attack (by bromide anion). In addition, the $\mathrm{CS}-\left[\mathrm{BuPh}_{3} \mathrm{P}\right] \mathrm{Br}$ performed well in five consecutive runs without any loss of PC yield and selectivity [112]. The CS-supported 1-ethyl-3-methyl imidazolium halides were also demonstrated to be recyclable and efficient under mild conditions [113]. It is noted that different from the above method for the immobilization of quaternary ammonium salt, Tharun et al. [114] prepared quaternized chitosan in situ by the reaction of $\mathrm{CH}_{3} \mathrm{I}$ with $-\mathrm{NH}_{2}$ on $\mathrm{CS}$.

As discussed above, the concept of multi-synergetic effects is applicable for the design of an efficient immobilized catalyst. It is meaningful to develop environment-benign, architecture well-ordered porous materials that are efficient for the adsorption of $\mathrm{CO}_{2}$ and epoxides. In addition, methods of chemical immobilization of active components should be developed to avoid catalyst deactivation due to leaching.

\subsection{Organic copolymer catalysts}

The use of organic copolymers as heterogeneous catalysts is highly desirable because they are cheap to prepare, easy to separate, and the catalytically active sites are tunable and high in density.

\subsubsection{Poly(ionic liquids) catalysts synthesized by olefin polymerization}

Imidazole ILs are efficient homogeneous catalysts for the cycloaddition of $\mathrm{CO}_{2}$ to epoxides. The development of poly(ionic liquids) (PILs) as a heterogeneous catalyst is beneficial in terms of catalyst separation.

Xie et al. [115] first synthesized highly crosslinked PILs by copolymerization of 3-butyl-1-vinylimidazolium chloride ([VBIM]Cl) with cross-linker divinylbenzene (DVB) (Fig. 13). 


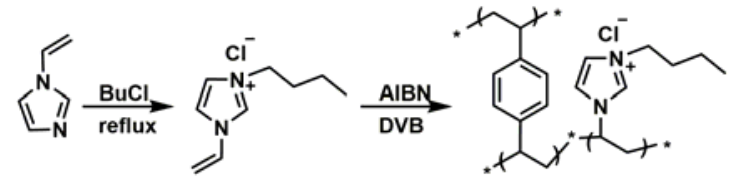

Fig. 13. Synthesis of the cross-linked PILs [115]. AIBN: azobis(isobutyronitrile).

The amount of [VBIM]Cl was $1 \mathrm{mmol}$ per $1 \mathrm{~g}$ PDVB-[VBIM]Cl. The catalytic activity of PDVB-[VBIM]Cl was comparable to or even better than those of the liquid catalysts [BMIM]Cl and [VBIM]Cl which are PSIL monomers. In the case of PDVB-[VBIM]Cl, the yield of $\mathrm{PC}$ was $97.4 \%$ at $110^{\circ} \mathrm{C}$ and $6 \mathrm{MPa}$ in $6 \mathrm{~h}$. In addition, PDVB-[VBIM]Cl showed much better performance than PVBIMCl that was synthesized by direct polymerization of [VBIM]Cl without the use of the cross-linker DVB. The above phenomenon was also seen in hydroxyl-, carboxyl- and amino-functionalized PILs with a similar framework [116]. This was ascribed to the much higher density of active sites in PVBIMCl compared to PDVB-[VBIM]Cl $[115,116]$. In addition, hydroxyl-, carboxyl- and aminofunctionalized PILs showed much higher catalytic activity than non-functionalized PILs. Using carboxyl-functionalized PILs as catalyst, $95 \%$ PC yield and 100\% selectivity was obtained at $120{ }^{\circ} \mathrm{C}$ and $2 \mathrm{MPa}$ in $4 \mathrm{~h}$ [116]. By means of suspension polymerization, Han et al. [117] prepared a series of PDVB-based PILs by reacting a variety of alkyl halides with highly cross-linked porous poly(N-vinylimidazole-codivinylbenzene) (PVIm) (Fig. 14). The results demonstrated that the improved catalytic activity of PVIm was related to factors such as more nucleophilic anions, bulkier alkyl chains, and presence of hydroxyl groups. Dani et al. [118] developed porous PILs that were high in surface area by an innovative method by the synthesis of a non-ionic co-polymer by precipitation polymerization, and the co-polymer was then quaternized by an alkylation step using microwave heating. The amount of ILs was $1.6 \mathrm{mmol} / \mathrm{g}$ PILs when the DVB : VIm volume ratio was 3:7. The yield of EC depended on the loading of VIm.

Besides the PDVB-based ILs, various cross-linked ionic polymers based on styrene-functionalized imidazolium salts were prepared by the direct polymerization of 1,3-bis(4vinylbenzyl)imidazolium salts ([bvbim] $\mathrm{X}, \mathrm{X}=\mathrm{Cl}, \mathrm{PF}_{6}$, or $\mathrm{BF}_{4}$ ). Poly[bvbim]Cl and [bvbim]Cl exhibited almost identical catalytic activity while catalytic activity over poly[bvbim]-[ $\left.\mathrm{PF}_{6}\right]$ and poly $[$ bvbim $]\left[\mathrm{BF}_{4}\right]$ was negligible. The results testified to the importance of nucleophilic anions [119]. In the work of Wang et al. [120], bis-vinylimidazolium salts (Fig. 15) were used as monomers, and in the free radical self-polymerization

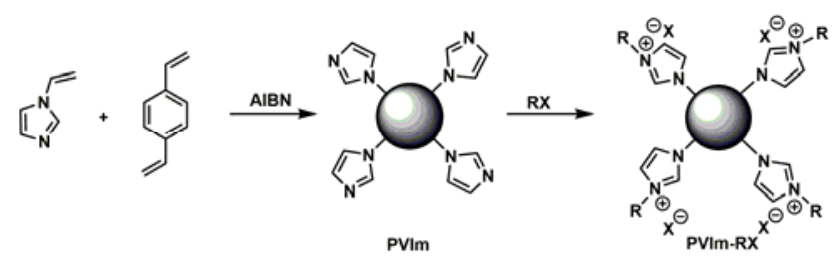

Fig. 14. Schematic for the synthesis of PVIm-RX [117].

process, meso-macroporous hierarchical PILs (MPILs) with tunable structure and extremely high ionic site density were formed. The MPILs were highly efficient for the cycloaddition reaction at atmospheric pressure and low temperature, in particular for epoxides with a long carbon chain that are known to be extremely inert. The excellent performance was ascribed to the porous structure being suitable for $\mathrm{CO}_{2}$ adsorption as well as to the enrichment of $\mathrm{Br}^{-}$anions needed for epoxide ring opening.

\subsubsection{Poly(ionic liquids) catalysts prepared by non-olefin polymerization}

The above PILs were all synthesized by olefin polymerization with the ILs located at the side chain which limited the loading of ILs and restricted the stability as well as the recyclability of PILs. By the reaction of 1,2,4,5-tetrakis(bromomethyl)benzene (TBB) and 4,4'-bipyridine, a new highly cross-linked cationic polymer (TBB-BPy) was synthesized. The material was generated as uniform microspheres with a smooth surface and size of 2-3 $\mu \mathrm{m}$. The activity of TBB-BPy was higher than that of TBB-Py and TBB-Py functionalized with hydroxyl, carboxyl or amino. In the case of TBB-BPy, the yield of PC reached $99 \%$ in $4 \mathrm{~h}\left(120{ }^{\circ} \mathrm{C}\right.$ and $1 \mathrm{MPa}$ ). In addition, with a cross-linked covalent cationic structure, the catalyst can be reused six times without loss of activity [121]. Yang et al. [122] adopted a two-step alkylation approach for the synthesis of fluoro-functionalized polymeric ILs (F-PIL-Br) with the ILs located at the main chain (Fig. 16). The resulting PILs were stable up to $300{ }^{\circ} \mathrm{C}$. The catalytic activity increased with fluorine content in the cations, following the order: PIL-Br $<\mathrm{F}_{0.5}$-PIL-Br $<$ F-PIL-Br. In addition, F-PIL-Br showed activity three times higher than that of non-fluorous PIL-Br in the cycloaddition of $\mathrm{CO}_{2}$ to SO. This may be due to the $\mathrm{CO}_{2}$-philic property of the fluorine-containing materials that enhanced $\mathrm{CO}_{2}$ adsorption around the catalytic sites [77]. Wang et al. prepared main chain poly-imidazolium salts by the condensation reaction of bisimidazoles and silicon tetrachloride (Fig. 17). The existence of $\mathrm{Si}-\mathrm{OH}$ in the poly-imidazolium salt was confirmed by the FT-IR stretching vibration signal at $3360 \mathrm{~cm}^{-1}$ and a ${ }^{1} \mathrm{H}$ NMR peak at $15.03 \mathrm{ppm}$. The experimental and DFT results evidenced that the presence

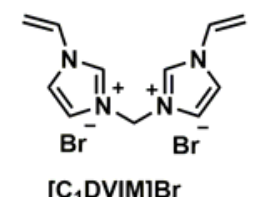

$\left[\mathrm{C}_{1} \mathrm{DVIM}\right] \mathrm{Br}$

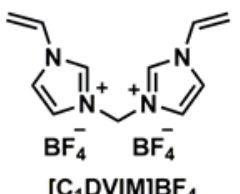

$\left[\mathrm{C}_{1} \mathrm{DVIM}_{\mathrm{B}} \mathrm{BF}_{4}\right.$

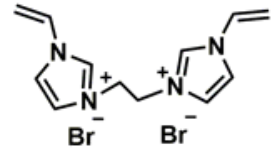

$\left[\mathrm{C}_{2} \mathrm{DVIM}\right] \mathrm{Br}$

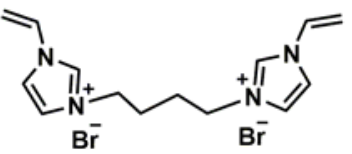

$\left[\mathrm{C}_{4} \mathrm{DVIM}\right] \mathrm{Br}$

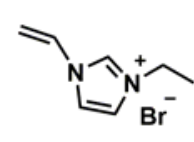

$\left[\mathrm{C}_{2} \mathrm{VIM}\right] \mathrm{Br}$

Fig. 15. Structure of synthesized vinylimidazolium salt monomers [120]. 

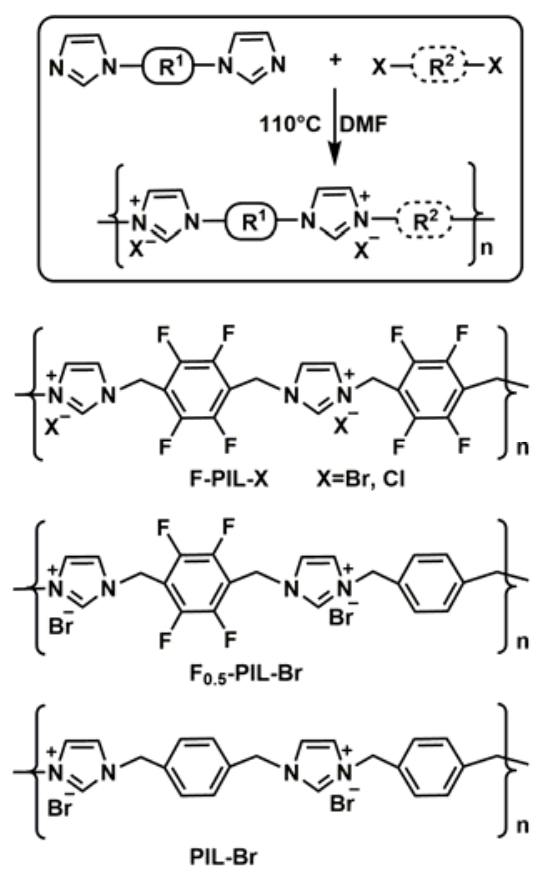

Fig. 16. Synthetic route and structures of fluoro-functionalized polymeric ILs [122].

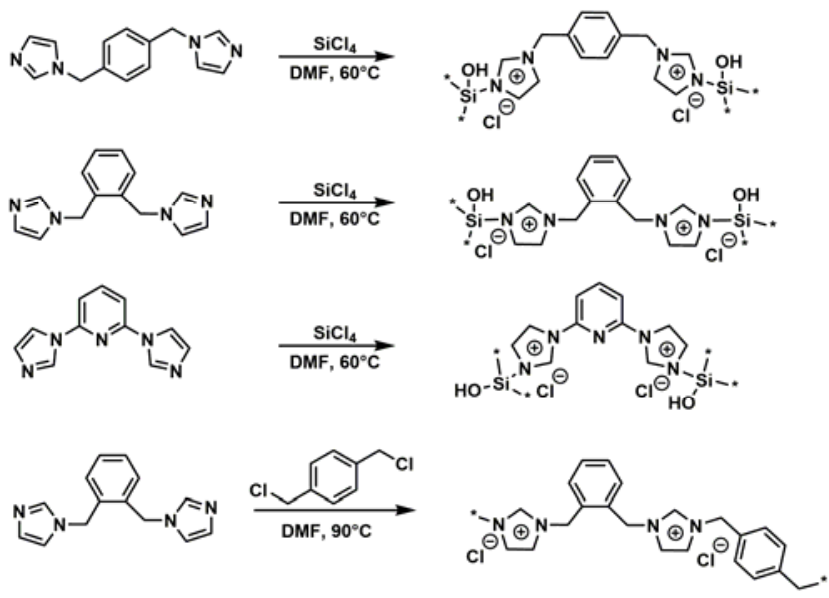

Fig. 17. Synthesis of main chain poly-imidazolium salts by condensation reaction of bisimidazoles and silicon tetrachloride [123].

of $\mathrm{Si}-\mathrm{OH}$ in the polymer chain was the key factor for achieving high activity [123].

Various novel hypercrosslinked porous polymers embedded with a phosphonium salt were prepared by the Friedel-Crafts reaction using phosphonium salts, benzene, and formaldehyde dimethyl acetal as monomer (Fig. 18). The surface area decreased with increasing anion diameter as well as alkyl chain length of cations. The pore size increased with increasing anion diameter of $\mathrm{Cl}^{-}, \mathrm{Br}^{-}$and $\mathrm{I}^{-}$. It was observed that the catalytic performance showed the order of $\mathrm{Br}^{-}>\mathrm{Cl}^{-}>\mathrm{I}^{-}$while $\mathrm{CO}_{2}$ capacity had the order of $\mathrm{Br}^{-}>\mathrm{Cl}^{-}>\mathrm{I}^{-}$. Hence, the high activity of the porous polymers with $\mathrm{Br}^{-}$was attributed to the combined effects of high $\mathrm{CO}_{2}$ capacity, suitable nucleophilicity and leaving ability of $\mathrm{Br}^{-}$as well as the large surface area and pore size [124].

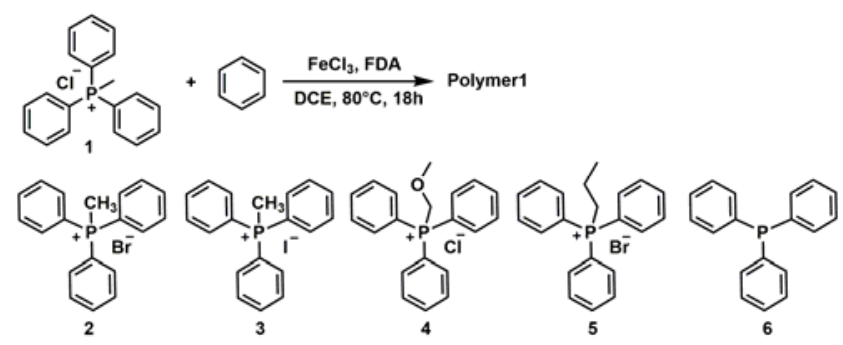

Fig. 18. Synthesis of hypercrosslinked phosphonium polymers [124].

\subsubsection{Halogen-free polymers catalysts}

Amorphous triazine-based covalent organic framework (CTF) was prepared by thermal polymerization of 1,4-dicyanobenzene or 2,6-dicyanopyridine (Fig. 19). With high thermal and chemical stability, the CTF with abundant basic nitrogen sites was an efficient catalyst for $\mathrm{CO}_{2}$ cycloaddition to epoxides. The mesopores, large surface area and high nitrogen content were beneficial for the conversion of $\mathrm{CO}_{2}$ and epoxides [125]. With abundant amino and hydroxyl groups, dicyandiamide-formaldehyde polymer (DFP) was apt for the cycloaddition reaction. The mechanism involves the ring-opening of epoxides assisted by the hydroxyl, and the activation of $\mathrm{CO}_{2}$ induced by amine. In addition, the introduction of ammonium salts markedly enhanced the activity of DFP [126]. A nanoporous polymer-based NHC (NP-NHC) with an excellent 3D microporous structure, relatively high specific surface area, and large pore volume was prepared (Fig. 20). The super basic nature of NP-NHC facilitated its reaction with $\mathrm{CO}_{2}$ to afford the corresponding carbonate adducts with $97 \% \mathrm{CO}_{2}$ fixation efficiency at room temperature. In the cycloaddition of $\mathrm{CO}_{2}$ and epoxides, NP-NHC showed excellent performance comparable to NHC, and showed unique substrate selectivity due to its microporous structure $(0.4 \mathrm{~nm})$. NP-NHC effectively catalyzed $\mathrm{CO}_{2}$ cycloaddition to monoaliphatic substituted terminal epoxides, affording the corresponding cyclic carbonates in excellent yields (92\%-98\%) and 100\% selectivity. However, the product yield was bad with phenyl and benzyl substituted epoxides. The product yield was in trace amount (1\%) for the former and zero for the latter [23].

The above polymer catalysts are mainly prepared by olefin polymerization, and showed poor chemical and thermal

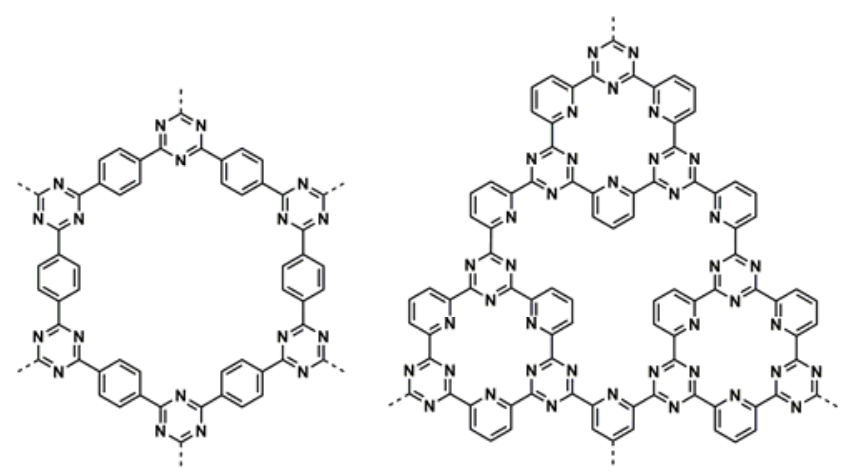

Fig. 19. Structures of covalent triazine frameworks: CTF-1 (left) and CTF-P (right) [125]. 


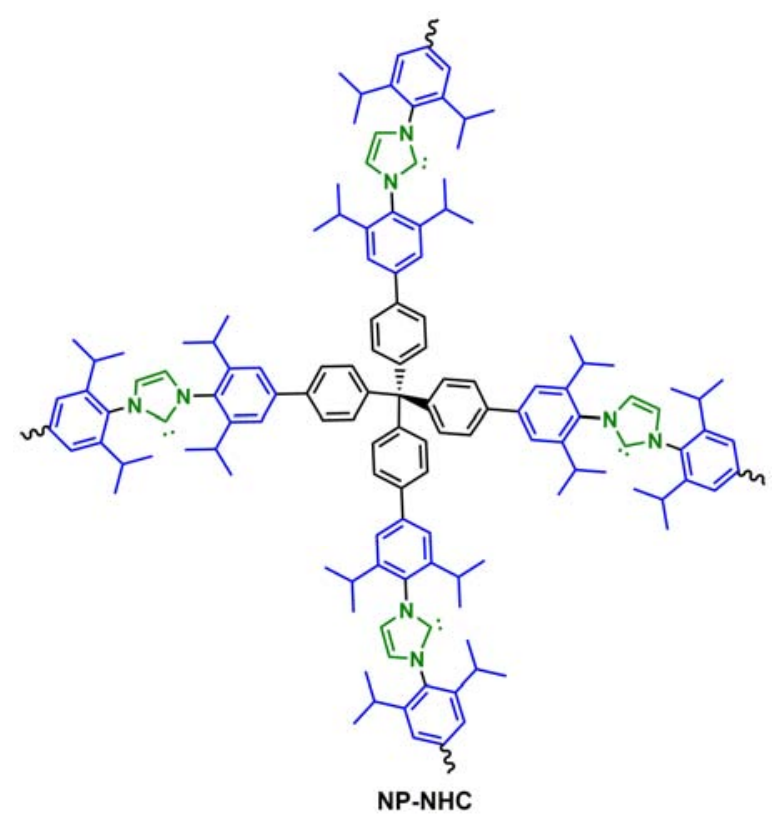

Fig. 20. Structure of nanoporous polymer based NHC [23].

stability. In addition, the problem of swelling typical of olefin polymers is inevitable. Therefore, the design of an innovative monomer and development of a method for the preparation of a well-ordered architecture and nanoporous polymer with high stability and low swelling tendency is desirable. It is envisaged that the fabrication of polymer-containing composite materials is a way to tackle the problems.

\subsection{Carbon materials}

Recently, carbon materials have received increasing attention as metal-free heterogeneous catalysts owing to easy access from natural sources, ease of preparation and regeneration, excellent thermal and chemical stability, and high specific surface area. With the easy recovery feature, carbon materials exhibit advantages in terms of activity and regenerability over traditional metal-containing catalysts due to their high flexibility for pore structure modification and surface functionalization [127]. There are many carbon materials such as graphene oxide (GO) and graphitic carbon nitride $\left(\mathrm{g}-\mathrm{C}_{3} \mathrm{~N}_{4}\right)$ used in cycloaddition reactions. Most of these are listed in Table 2.

\subsubsection{Catalysts based on carbon nitride}

g- $\mathrm{C}_{3} \mathrm{~N}_{4}$ is a polymeric carbon material mainly made up of $\mathrm{C}$ and $\mathrm{N}$ atoms connected in tris-triazine-based patterns, with $\mathrm{H}$ being the major impurity. Being rich in nitrogen species of different kinds, $\mathrm{g}-\mathrm{C}_{3} \mathrm{~N}_{4}$ is $\mathrm{CO}_{2}$-phillic and can be used for $\mathrm{CO}_{2}$ adsorption and activation. Ansari et al. [128] first applied mesoporous carbon nitrides (MCN) prepared by a nano-casting method using mesoporous silica as template and melamine as precursor for $\mathrm{CO}_{2}$ cycloaddition to PO. However, a low activity was recorded despite the use of a massive amount of DMF as solvent.

Many methods were explored to enhance the activity of g- $\mathrm{C}_{3} \mathrm{~N}_{4}$, including the enhancement of defect sites [129], increase of surface area [130], introduction of Lewis acidic sites and immobilization of functional groups [131-133]. Urea-derived $\mathrm{g}-\mathrm{C}_{3} \mathrm{~N}_{4}$ with a higher stability and more active centers was prepared at different temperatures $\left(450-550{ }^{\circ} \mathrm{C}\right)$. With a decrease of preparation temperature from $550{ }^{\circ} \mathrm{C}$ to 480 ${ }^{\circ} \mathrm{C}$, g- $\mathrm{C}_{3} \mathrm{~N}_{4}$ with lower crystallinity and smaller polymerization degree was generated. Due to the enhanced amount of edge defects, there was higher catalytic activity. Using $\mathrm{u}-\mathrm{g}-\mathrm{C}_{3} \mathrm{~N}_{4}-480$ as catalyst, complete conversion and high yield (98.9\%) of PC was attained at $130{ }^{\circ} \mathrm{C}, 2 \mathrm{MPa}$ and $24 \mathrm{~h}$ [129]. In order to enlarge surface area, $\mathrm{g}-\mathrm{C}_{3} \mathrm{~N}_{4}$ nanophases were well dispersed in SBA-15 mesochannels by two-step vapor condensation of dicyandiamide. It was demonstrated that the defect-rich $g-\mathrm{C}_{3} \mathrm{~N}_{4}$ nanophases were active for the cycloaddition reaction.

Table 2

Catalytic performance of various carbocatalysts for the cycloaddition of $\mathrm{CO}_{2}$ to $\mathrm{PO}$.

\begin{tabular}{|c|c|c|c|c|c|c|c|}
\hline Catalyst & Temperature $\left({ }^{\circ} \mathrm{C}\right)$ & Pressure (MPa) & Time (h) & $m$ (cat.) (mg) & $n(\mathrm{PO})(\mathrm{mmol})$ & Yield (\%) & TOFa $\left(\mathrm{h}^{-1}\right)$ \\
\hline MS-MCN & 140 & 0.6 & 10 & 20 & 21.5 & 30.6 & 3.3 [128] \\
\hline u-g- $\mathrm{C}_{3} \mathrm{~N}_{4}-480$ & 130 & 2 & 4 & 100 & 21.5 & 58.4 & $3.2[129]$ \\
\hline $\mathrm{Zn}^{2+} / \mathrm{g}-\mathrm{C}_{3} \mathrm{~N}_{4} / \mathrm{SBA}-15$ & 150 & 3.5 & 1.5 & 100 & 42.9 & 96.1 & $28.1[130]$ \\
\hline$n$-butBr/mp-C ${ }_{3} \mathrm{~N}_{4}$ & 140 & 2.5 & 6 & 200 & 143 & 87.7 & $10.7[132]$ \\
\hline $\mathrm{g}-\mathrm{C}_{3} \mathrm{~N}_{4} \mathrm{~b}$ & 130 & 3.5 & 2 & 50 & 64 & 5.6 & $3.3[133]$ \\
\hline $\mathrm{g}-\mathrm{C}_{3} \mathrm{~N}_{4}-\mathrm{S}^{\mathrm{b}}$ & 130 & 3.5 & 2 & 50 & 64 & 99.1 & $58.1[133]$ \\
\hline $\mathrm{Bu}_{4} \mathrm{NBr} / \mathrm{P}-\mathrm{C}_{3} \mathrm{~N}_{4}-2^{\mathrm{c}}$ & 100 & 2 & 4 & 50 & 28.6 & 93.1 & $13.3[131]$ \\
\hline $\mathrm{Bu}_{4} \mathrm{NBr} / \mathrm{Si} / \mathrm{SiC} @ \mathrm{C}^{\mathrm{d}}$ & 45 & 1 & 10 & 40 & 28.5 & 96.0 & $7.0[139]$ \\
\hline $\mathrm{Bu}_{4} \mathrm{NBr} / \mathrm{GO}$ & 100 & 2.25 & 1 & 50 & 28.6 & 81.3 & $47.4[25]$ \\
\hline $\mathrm{Bu}_{4} \mathrm{NI} / \mathrm{AP}-\mathrm{GO}^{\mathrm{f}}$ & 70 & 1 & 12 & 30 & 10 & 91 & $2.6[135]$ \\
\hline [BMIM]Br/GOg & 80 & 1 & 6 & 20 & 6 & 99 & $3.1[134]$ \\
\hline GO-[SmIm]I & 140 & 2 & 4 & 600 & 214 & 96 & $8.7[137]$ \\
\hline GO-HEIMBr & 140 & 2 & 4 & 400 & 214 & 99 & $13.5[138]$ \\
\hline GO-DMEDA-I & 120 & 2 & 3 & 100 & 28.6 & 89.4 & $8.7[136]$ \\
\hline GO-DMEDA-I & 140 & 2 & 0.5 & 125 & 28.6 & 99.4 & $46.4[136]$ \\
\hline $\mathrm{CNT}-\left(\mathrm{CH}_{2}\right)_{3}(\mathrm{Et})_{3} \mathrm{~N}^{+} \mathrm{Cl}^{-}$ & 110 & 2 & 6 & 660 & 214 & 66 & $3.6[140]$ \\
\hline $\mathrm{AA}-950^{\mathrm{b}}$ & 150 & 4 & 16 & 5 & 20 & 84.3 & $28.7[142]$ \\
\hline CNFWs & 150 & 2 & 12 & 10 & 20 & 86 & $14.6[143]$ \\
\hline
\end{tabular}

${ }^{a}$ Mass of synthesized cyclic carbonate over per gram carbocatalyst per hour. ${ }^{b}$ Using ECH as substrate. ${ }^{c}$ Using 2.4 mol\% Bu ${ }_{4} \mathrm{NBr}$ as co-catalyst. ${ }^{\mathrm{d}} \mathrm{Using} 3$ $\mathrm{mol} \% \mathrm{Bu}_{4} \mathrm{NBr}$ as co-catalyst. ${ }^{\mathrm{e}}$ Using $2.5 \mathrm{~mol} \% \mathrm{Bu}_{4} \mathrm{NBr}$ as co-catalyst. ${ }^{\mathrm{f}}$ Using $1 \mathrm{~mol} \% \mathrm{Bu} 4 \mathrm{NI}$ as co-catalyst. $\mathrm{g}$ Using $2.5 \mathrm{~mol} \%$ [BMIM] Br as co-catalyst. 
Moreover, the introduction of Lewis acid sites was an efficient way to improve activity [130]. However, the leaching of the active ions was an inevitable problem. Therefore, Lan et al. [131] designed a simple and efficient method to prepare P-modified g- $\mathrm{C}_{3} \mathrm{~N}_{4}\left(\mathrm{P}-\mathrm{C}_{3} \mathrm{~N}_{4}\right)$ with acid sites by thermolysis of a mixture of melamine and hexachlorotriphosphazene under metal-free conditions. For the first time, acid-base bifunctional $\mathrm{P}-\mathrm{C}_{3} \mathrm{~N}_{4}$ combined with $\mathrm{Bu} 4 \mathrm{NBr}$ was used as catalyst for the synthesis of cyclic carbonates by $\mathrm{CO}_{2}$ cycloaddition to epoxides under mild conditions. It was observed that the catalytic activity of $\mathrm{P}-\mathrm{C}_{3} \mathrm{~N}_{4}$ increased with $\mathrm{P}$ content as a result of the formation of acid sites. $\mathrm{P}-\mathrm{C}_{3} \mathrm{~N}_{4}-2$ exhibited the best activity with a PC yield of $94.6 \%$ at $90{ }^{\circ} \mathrm{C}$ and $2 \mathrm{MPa}$ in $4 \mathrm{~h}$. The excellent performance of $\mathrm{Bu}_{4} \mathrm{NBr} / \mathrm{P}-\mathrm{C}_{3} \mathrm{~N}_{4}-2$ was attributed to the synergetic effect of the acid sites and halide anions for ring opening of epoxide as well as to the basic sites for adsorption and activation of $\mathrm{CO}_{2}$.

New mesoporous- $\mathrm{C}_{3} \mathrm{~N}_{4} \quad\left(\mathrm{mp}-\mathrm{C}_{3} \mathrm{~N}_{4}\right)$ based quaternary ammonium salts were prepared by the reaction of tertiary amine on mp- $\mathrm{C}_{3} \mathrm{~N}_{4}$ with alkyl halides. For the alkyl halides with long alkyl chains, the corresponding $m p-\mathrm{C}_{3} \mathrm{~N}_{4}$ showed low activity due to steric hindrance during the reaction with the $\mathrm{N}$-containing heterocycles of $\mathrm{mp}-\mathrm{C}_{3} \mathrm{~N}_{4}$. The halide anions and the amine species located at the edges of $\mathrm{mp}-\mathrm{C}_{3} \mathrm{~N}_{4}$ sheets were suggested to be the catalytically active species. The former activate the PO molecules while the latter promote the adsorption and activation of $\mathrm{CO}_{2}$ [132]. Recently, Huang et al. [133] prepared amino- and hydroxyl-rich $\mathrm{g}-\mathrm{C}_{3} \mathrm{~N}_{4}$ by the hydrolysis of $\mathrm{g}-\mathrm{C}_{3} \mathrm{~N}_{4}$ in $60 \% \mathrm{H}_{2} \mathrm{SO}_{4}$. The catalytic activity of g- $\mathrm{C}_{3} \mathrm{~N}_{4}$ increased with the increase of $\mathrm{H}_{2} \mathrm{SO}_{4}$ treatment temperature from 40 to $80{ }^{\circ} \mathrm{C}$. Further rise of temperature to $100{ }^{\circ} \mathrm{C}$ resulted in the dissolution of $\mathrm{g}-\mathrm{C}_{3} \mathrm{~N}_{4}$ in $\mathrm{H}_{2} \mathrm{SO}_{4}$ to form a clear solution. It was considered that the enhanced catalytic activity was a result of enlarged specific surface area as well as the generation of amino and hydroxyl groups.

\subsubsection{Catalysts based on graphene oxide}

Being rich in oxygen functional groups (e.g., hydroxyl, epoxide, carbonyl, and carboxyl), GO has received increasing attention as a metal-free heterogeneous catalyst owing to outstanding features such as water-tolerance, high adsorption capacity, easy modification, 2D morphology and sheet structure. Lan et al. [25] reported that GO exhibited excellent catalytic performance in the cycloaddition of $\mathrm{CO}_{2}$ with epoxides under mild conditions in the presence of $\mathrm{Bu}_{4} \mathrm{NBr}$. With $\mathrm{PO}$ as substrate, $96 \%$ yield of PC was afforded in $1 \mathrm{~h}\left(100{ }^{\circ} \mathrm{C}\right.$ and $2 \mathrm{MPa}$ ), and at room temperature and atmospheric pressure, the PC yield was $79 \%$ in $48 \mathrm{~h}$. The synergetic action of the hydroxyl group and nucleophilic anion was proved by FT-IR. In addition, the presence of a proper amount of $\mathrm{H}_{2} \mathrm{O}$ enhanced the conversion of epoxide remarkably. Subsequently, Luo et al. [134] conducted a kinetics study on the cycloaddition of $\mathrm{CO}_{2}$ to SO over imidazolium IL/GO binary catalyst. Recently, Saptal et al. [135] designed (3-aminopropyl)-trimethoxysilane functionalized GO (APGO) with acid-base cooperative catalytic functions. The presence of HBDs (acid) and amines (base), and the porous nature of AP-GO were essential factors for the

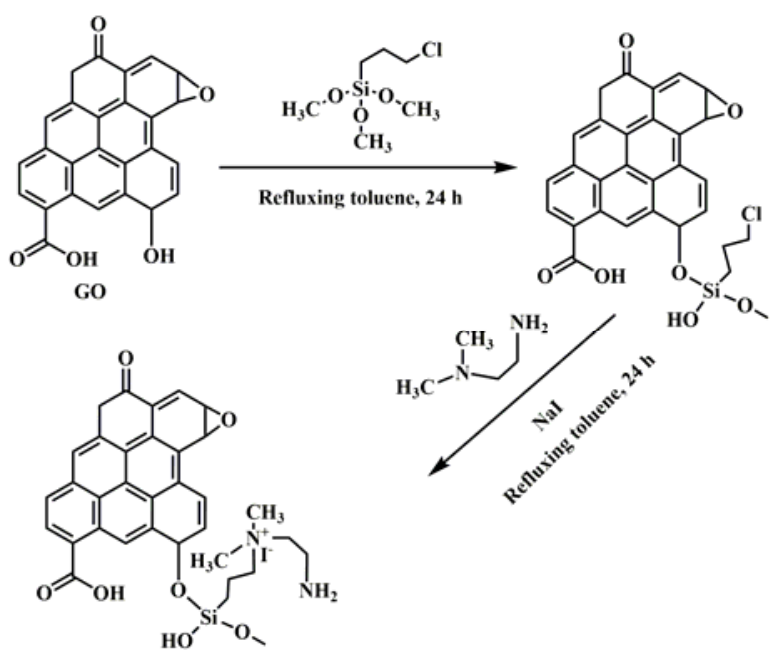

Fig. 21. Preparation of GO grafted with quaternary ammonium salts bearing terminal amino groups [136].

promotion of the cycloaddition reaction. Combined with TBAI, AP-GO was efficient for the synthesis of cyclic carbonates at $100{ }^{\circ} \mathrm{C}$ and atmospheric pressure, and 94\% yield of SC was obtained in $27 \mathrm{~h}$. Nonetheless, the recycle of homogeneous nucleophiles is complex.

Recently, Lan et al. [136] functionalized GO with silanol group, amine and quaternary ammonium salts by silylanization of GO with chlorine-terminal silanes followed by subsequent nucleophilic substitution reaction with $N, N$ '-dimethylethylenediamine through a one-pot approach (Fig. 21). It was found that the multi-functionalized GO was a water-tolerant and recyclable catalyst effective for the cycloaddition reaction at $120{ }^{\circ} \mathrm{C}$ and $2 \mathrm{MPa}$ with a yield of $97.8 \%$ in $4 \mathrm{~h}$. The non-toxic, metal-free, water-tolerant, and high-efficiency catalyst showed a TOF of $46.4 \mathrm{~h}^{-1}$ under mild condition, which was the highest among the reported heterogeneous carbocatalysts. The excellent performance was attributed to the synergetic effect of the silanol group and halide anion for epoxide ring opening as well as the ability of amine for the adsorption and activation of $\mathrm{CO}_{2}$. $\mathrm{Li}$ and coworkers $[137,138]$ immobilized imidazole ILs and hydroxyl-functionalized ILs on GO using the method reported by Lan et al. [136]. The presence of hydroxyl groups was responsible for the high catalytic performance of the GO that was grafted with hydroxyl-functionalized ILs. The hydroxyl groups provided efficient synergistic sites to accelerate the ring opening of epoxide. The supported catalyst can be easily separated and reused for at least seven times without significant loss of activity.

\subsection{Other carbon materials}

Liu et al. [139] synthesized hollow-structured Si/SiC@C nanospheres (HSSC) with high specific surface areas (BET 239 $\mathrm{m}^{2} / \mathrm{g}$ ) by magnesiothermic reduction of resin-coated $\mathrm{SiO}_{2}$ spheres. A PC yield of $96 \%$ was obtained over TBAB/HSSC at $45^{\circ} \mathrm{C}$ and $1.0 \mathrm{MPa}$ in $10 \mathrm{~h}$. Different from the TBAB/GO catalyst system, the excellent performance was attributed to the synergetic effect between Brönsted acid (HSSC) and Lewis base 
(TBAB) as well as to the high surface area and porosity of HSSC. Other carbon materials were used to graft ILs. Different from the process for the generation of GO-based ILs [136-138], the carbon nanotube-supported quaternary ammonium salts (QCNT) were synthesized by acylation (reaction of carboxyl groups on oxidized carbon nanotube with thionyl chloride) and esterification (reaction of acyl chloride with hydroxyl on functionalized quaternary salts). The cycloaddition reaction of $\mathrm{CO}_{2}$ with epoxides over QCNT followed first order kinetics, at least for the first $3 \mathrm{~h}$. In addition, a synergy was observed between the carboxyl and the ammonium moiety grafted on the carbon nanotubes, and the distance between carboxyl and quaternary $\mathrm{N}$ had a strong impact on the cycloaddition reaction [140]. Coconut shell activated carbon (CSAC) grafted with ILs for the continuous cycloaddition of $\mathrm{CO}_{2}$ to $\mathrm{ECH}$ in a packed bed reactor. The conversion of $\mathrm{ECH}$ over the CSAC tethered $\mathrm{Bmim} / \mathrm{Br}, \mathrm{Bmim} / \mathrm{BF}_{4}, \mathrm{Bmim}-\mathrm{OH} / \mathrm{Br}$ and $\mathrm{Bmim}-\mathrm{COOH} / \mathrm{Br}$ were $63.4 \%, 74.5 \%, 83.4 \%$ and $85.9 \%$ at $140{ }^{\circ} \mathrm{C}$ and $1.4 \mathrm{MPa}$ respectively. Hydroxyl or carboxyl groups on the CSAC grafted with Bmim- $\mathrm{OH} / \mathrm{Br}$ and $\mathrm{Bmim}-\mathrm{COOH} / \mathrm{Br}$ formed hydrogen bonds with the oxygen of $\mathrm{ECH}$, playing a synergistic role with $\mathrm{Br}^{-}$to enhance the cycloaddition reaction [141].

$\mathrm{N}$-doped carbon materials were efficient catalysts for the cycloadition reaction. In the work of Ma et al. [142], an N-doped porous carbon monolith with a large specific surface area was prepared from alginic acid at different pyrolysis temperatures (defined as AA-750, AA-850, AA-950, AA-1000). The rise of the pyrolysis temperature resulted in the decline of $\mathrm{N}$ content but enhancement of $\mathrm{CO}_{2}$ adsorption capacity and surface area (20 $\mathrm{mmol} / \mathrm{g}$ and $2486 \mathrm{~m}^{2} / \mathrm{g}$ for AA-1000). AA-950 showed the best catalytic activity in the cycloaddition of $\mathrm{CO}_{2}$ to $\mathrm{ECH}$ at $150{ }^{\circ} \mathrm{C}$ and $4 \mathrm{MPa}$ with a product yield of $84.3 \%$ in $16 \mathrm{~h}$. The high activity of AA-950 was ascribed to the synergic effect of surface area and pyridinic-N. Li et al. [143] also efficiently synthesized cyclic carbonates by the cycloaddition of $\mathrm{CO}_{2}$ to epoxides over nitrogen-doped porous carbon nanofiber webs (CNFWs) prepared by a one-step carbonization-activation treatment of pre-synthesized polypyrrole nanofiber webs. The CNFWs exhibited outstanding adsorption capacity (4.42 mmol/g) at 25 ${ }^{\circ} \mathrm{C}$ and $1 \mathrm{MPa}$. The cycloaddition reaction mechanism was related to the adsorption and activation of $\mathrm{CO}_{2}$ by Lewis base $\mathrm{N}$ sites as well as to the nucleophilic attack of pyridine $\mathrm{N}$ at epoxide activated by the hydroxyl group on CNFWs through hydrogen bonding.

However, the limited amounts of functional groups on carbon materials hinder the use of carbocatalysts. It is envisaged that the multi-hydroxyl and multi-cation concept together with the "multilayered covalently supported" approach can bring about activity improvement for carbocatalysts. Moreover, the development of the controlled synthesis of novel carbon materials as efficient catalysts is meaningful.

\section{Conclusions and perspectives}

Recent advances in the design of metal-free catalysts including organic bases, ILs, supported catalysts, organic copolymers and carbon materials as well as progress in the cycloaddition mechanism were discussed. The synergistic effects were described in detail at the molecular level. The cooperative effects of HBDs and organic bases, organic bases and nucleophilic anions, HBDs and nucleophilic anions as well as that of the active component and support for the enhancement of catalytic activity were emphasized. The review affords insights into the design and development of efficient metal-free catalytic systems. The ultimate challenge is to design efficient metal-free catalytic systems for flow reactors where the cycloaddition reaction is conducted at ambient temperature and atmospheric pressure using $\mathrm{CO}_{2}$ of low concentration such as "waste" $\mathrm{CO}_{2}$. For $\mathrm{CO}_{2}$ adsorption as well as the activation of $\mathrm{CO}_{2}$ and epoxides, the use of the multi-synergetic strategy is advisable for the development of a suitable catalyst system for the cycloaddition reaction. The multi-functional approach was highlighted. In addition, DFT calculations are recommended for the advanced design of catalysts and better understanding of the catalytic mechanism.

\section{Abbreviations}

$\begin{array}{ll}\text { HBDs } & \text { Hydrogen bond donors } \\ \text { DFT } & \text { Density functional theory } \\ \text { ILs } & \text { Ionic liquids } \\ \text { NHCs } & \text { N-heterocyclic carbenes } \\ \text { TBD } & \text { 1,5,7-Triaza-bicyclo[4.4.0]dec-5-enium } \\ \text { DBU } & \text { 1,8-Diazabicyclo-[5.4.0]undec-7-ene } \\ \text { NHC-CO } & \text { Imidazolium carboxylates } \\ \text { IPr-CO2 } & \text { 1,3-Bis(2,6-diisopropylphenyl) } \\ & \text { imidazolium-2-carboxylate } \\ \text { PO } & \text { Propylene oxide } \\ \text { PC } & \text { Propylene carbonate } \\ \text { IBu-CO } & \\ \text { NHO } & \text { 1,3-Ditert- butylimidazolium-2-carboxylate } \\ \text { SC } & \text { N-Heterocyclic olefin } \\ \text { DMAP } & \text { Styrene carbonate } \\ \text { DABCO } & \text { N,N-dimethylaminopyridine } \\ \text { TEOA } & \text { 1,4-Diazabicyclo[2.2.2]octane } \\ \text { DEOA } & \text { Diethanolamine } \\ \text { MEOA } & \text { Monoethanolamine } \\ \text { Im } & \text { Imidazole } \\ \text { Py } & \text { Pyridine } \\ \text { TEA } & \text { Triethylamine } \\ \text { DEA } & \text { Diethylamine } \\ \text { PEG600 } & \text { Poly(ethylene glycol)-600 } \\ \text { PEG400 } & \text { Poly(ethylene glycol)-400 } \\ \beta \text {-CD } & \text { } \text {-cyclodextrin } \\ \text { PG } & \text { 1,2-Propylene glycol } \\ 2 \text {-Py-EtOH } & \text { 2-Pyridinemethanol } \\ \text { ECH } & \text { Epichlorohydrin } \\ \text { NBS } & \text { N-bromosuccinimide } \\ \text { BPO } & \text { Benzoyl peroxide } \\ \text { SO } & \text { Styrene oxide } \\ \text { PETT } & \text { Pentaerythritol } \\ \text { TA } & \text { Tannic acid } \\ \text { HEMIM } & \text { 1-(2-Hydroxyl-ethyl)-3-methylimidazolium } \\ & \end{array}$




\section{Graphical Abstract}

Chin. J. Catal., 2016, 37: 826-845 doi: 10.1016/S1872-2067(15)61085-3

Recent advances in metal-free catalysts for the synthesis of cyclic carbonates from $\mathrm{CO}_{2}$ and epoxides

Dong-Hui Lan, Na Fan, Ying Wang, Xian Gao, Ping Zhang, Lang Chen, Chak-Tong Au, Shuang-Feng Yin*

Hunan University; Hunan Institute of Engineering

Synergistic effects in metal-free catalysts for the synthesis of cyclic carbonates from $\mathrm{CO}_{2}$ and epoxides are described in detail at the molecular level.

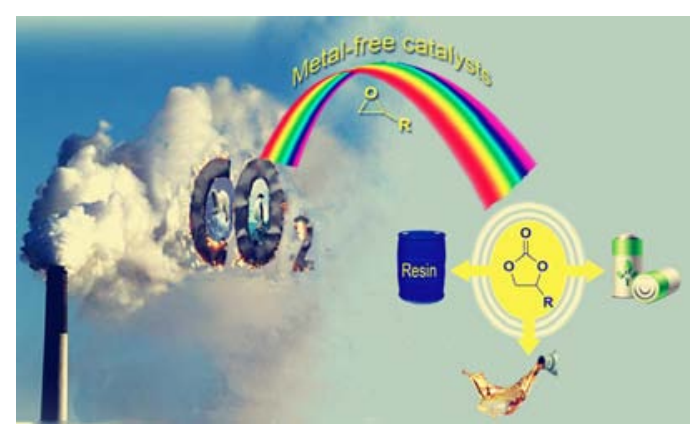

HEBimBr 1-(2-Hydroxyl-ethyl)-3-butylimidazolium bromide

P-ylide UDILs Phosphorus ylide

AAs

HEPIMBr

rea derivatives ILs $\alpha$-Amino acids

POSS-Imi Polyhedral oligomeric silsesquioxane functionalized with imidazolium chloride peripheries

PS

$\mathrm{CS}$

[VBIM]Cl DVB PVIm AIBN [bvbim]X MPILs TBB TBB-BPy F-PIL-Br CTF DFP g- $\mathrm{C}_{3} \mathrm{~N}_{4}$ Polystyrene Chitosan 3-Butyl-1-vinylimidazolium chloride Divinylbenzene Poly(N-vinylimidazole-co-divinylbenzene) Azobis(isobutyronitrile) 1,3-bis(4-vinylbenzyl)imidazolium salts Meso-macroporous hierarchical PILs 1,2,4,5-Tetrakis(bromomethyl)benzene Cross-linked cationic polymer Fluoro-functionalized polymeric ILs Triazine-based covalent organic framework Dicyandiamide-formaldehyde polymer Graphitic carbon nitride $\mathrm{P}-\mathrm{C}_{3} \mathrm{~N}_{4}$

GO

$\mathrm{mp}-\mathrm{C}_{3} \mathrm{~N}_{4}$ HSSC QCNT

CSAC CNFWs P-modified g- $\mathrm{C}_{3} \mathrm{~N}_{4}$ Graphene oxide Mesoporous- $\mathrm{C}_{3} \mathrm{~N}_{4}$ Hollow-structured Si/SiC@C nanospheres Carbon nanotube-supported quaternary ammonium salts Coconut shell activated carbon Nitrogen-doped porous carbon nanofiber webs

\section{References}

[1] R. Monastersky, Nature, 2013, 497, 13-14.

[2] M. Liu, J. B. Wu, X. D. Zhu, H. L. He, W. X. Jia, W. N. Xiang, Atmo. Environ., 2015, 114, 75-82.

[3] E. V. Kondratenko, G. Mul, J. Baltrusaitis, G. O. Larrazábal, J. Pérez-Ramírez, Energy Environ. Sci., 2013, 6, 3112-3135.

[4] A. A. Lacis, G. A. Schmidt, D. Rind, R. A. Ruedy, Science, 2010, 330, 356-359.

[5] S. Mathesius, M. Hofmann, K. Caldeira, H. J. Schellnhuber, Nat. Clim.
Change, 2015, 5, 1107-1113.

[6] W. H. Wang, Y. Himeda, J. T. Muckerman, G. F. Manbeck, E. Fujita, Chem. Rev., 2015, 115, 12936-12937.

[7] M. Aresta, A. Dibenedetto, A. Angelini, Chem. Rev., 2014, 114, 1709-1742.

[8] C. C. Chong, R. Kinjo, Angew. Chem. Int. Ed., 2015, 54, 1211612120.

[9] T. Sakakura, J. C. Choi, H. Yasuda, Chem. Rev., 2007, 107, 2365-2387.

[10] A. Padwa, S. S. Murphree, RKIVOC, 2006, 6-33.

[11] V. D'Elia, J. D. A. Pelletier, J. M. Basset, ChemCatChem, 2015, 7, 1906-1917.

[12] S. Klaus, M. W. Lehenmeier, C. E. Anderson, B. Rieger, Coordin. Chem. Rev., 2011, 255, 1460-1479.

[13] Z. Z. Yang, L. N. He, J. Gao, A. H. Liu, B. Yu, Energy Environ. Sci., 2012, 5, 6602-6639.

[14] L. N. He, Y. Du, J. Q. Wang, C. X. Miao, J. L. Wang, Z. Z. Yang, A. H. Liu, B. Yu, Y. N. Li, D. L. Kong, J. Gao, X. Y. Du, B. Li, Q. W. Song, R. Ma, Y. N. Zhao, Z. F. Diao, F. Wu, Chemistry of Carbon Dioxide, Science Press, Beijing, 2013, 42-44.

[15] Y. Chen, R. H. Qiu, X. H. Xu, C. T. Au, S. F. Yin, RSC Adv., 2014, 4, 11907-11918.

[16] T. Yano, H. Matsui, T. Koike, H. Ishiguro, H. Fujihara, M. Yoshihara, T. Maeshima, Chem. Commun., 1997, 1129-1130.

[17] T. Ema, K. Fukuhara, T. Sakai, M. Ohbo, F. Q. Bai, J. Y. Hasegawa, Catal. Sci. Technol., 2015, 5, 2314-2321.

[18] J. Ma, J. L. Liu, Z. F. Zhang, B. X. Han, Green Chem., 2012, 14, 2410-2420.

[19] Y. Y. Song, C. Cheng, H. W. Jing, Chem. Eur. J., 2014, 20, 12894-12900.

[20] C. Martín, G. Fiorani, A. W. Kleij, ACS Catal., 2015, 5, 1353-1370.

[21] K. Yamaguchi, K. Ebitani, T. Yoshida, H. Yoshida, K. Kaneda, J. Am. Chem. Soc., 1999, 121, 4526-4527.

[22] V. D’Elia, H. L. Dong, A. J. Rossini, C. M. Widdifield, S. V. C. Vummaleti, Y. Minenkov, A. Poater, E. Abou-Hamad, J. D. A. Pelletier, L. Cavallo, L. Emsley, J. M. Basset, J. Am. Chem. Soc., 2015, 137, 7728-7739

[23] S. N. Talapaneni, O. Buyukcakir, S. H. Je, S. Srinivasan, Y. Seo, K. Polychronopoulou, A. Coskun, Chem. Mater., 2015, 27, 6818-6826.

[24] Z. Zhou, C. He, J. H. Xiu, L. Yang, C. Y. Duan, J. Am. Chem. Soc., 2015, 137, 15066-15069.

[25] D. H. Lan, F. M. Yang, S. L. Luo, C. T. Au, S. F. Yin, Carbon, 2014, 73, 351-360.

[26] G. Fiorani, W. S. Guo, A. W. Kleij, Green Chem., 2015, 17, 
1375-1389.

[27] B. H. Xu, J. Q. Wang, J. Sun, Y. Huang, J. P. Zhang, X. P. Zhang, S. J. Zhang, Green Chem., 2014, 17, 108-122.

[28] W. N. R. W. Isahak, Z. A. C. Ramli, M. W. M. Hisham, M. A. Yarmo, Renew. Sust. Energy Rev., 2015, 47, 93-106.

[29] A. C. Kathalikkattil, R. Babu, J. Tharun, R. Roshan, D. W. Park, Catal. Surv. Asia, 2015, 19, 223-235.

[30] J. W. Comerford, I. D. V. Ingram, M. North, X. Wu, Green Chem., 2015, 17, 1966-1987.

[31] C. Martín, G. Fiorani, A. W. Kleij, ACS Catal., 2015, 5, 1353-1370.

[32] X. D. Lang, X. F. Liu, L. N. He, Curr. Org. Chem., 2015, 19, 681-694.

[33] R. M. Izatt, S. R. Izatt, R. L. Bruening, N. E. Izatta, B. A. Moyer, Chem. Soc. Rev., 2014, 43, 2451-2475.

[34] K. M. K. Yu, I. Curcic, J. Gabriel, H. Morganstewart, S. C. Tsang, J. Phys. Chem. A, 2010, 114, 3863-3872.

[35] Y. Kayaki, M. Yamamoto, T. Ikariya, Angew. Chem. Int. Ed., 2009, 48, 4194-4197.

[36] X. H. Zhang, N. Zhao, W. Wei, Y. H. Sun, Catal. Today, 2006, 115, 102-106.

[37] D. J. Heldebrant, P. G. Jessop, C. A. Thomas, C. A. Eckert, C. L. Liotta, J. Org. Chem., 2005, 70, 5335-5338.

[38] A. Barbarini, R. Maggi, A. Mazzacani, G. Mori, G. Sartori, R. Sartorio, Tetrahedron Lett., 2003, 44, 2931-2934.

[39] L. Wang, G. Y. Zhang, K. Kodama, T. Hirose, Green Chem., 2016, 18 , 1229-1233.

[40] H. Zhou, W. Z. Zhang, C. H. Liu, J. P. Qu, X. B. Lu, J. Org. Chem., 2008 73, 8039-8044.

[41] M. J. Ajitha, C. H. Suresh, Tetrahedron Lett., 2011, 52, 5403-5406.

[42] Y. B. Wang, Y. M. Wang, W. Z. Zhang, X. B. Lu, J. Am. Chem. Soc., 2013, 135, 11996-12003.

[43] Y. B. Wang, D. S. Sun, H. Zhou, W. Z. Zhang, X. B. Lu, Green Chem., 2015, 17, 4009-4015.

[44] H. K. He, M. J. Zhong, D. Konkolewicz, K. Yacatto, T. Rappold, G. Sugar, N. E. David, J. Gelb, N. Kotwal, A. Merkle, K. Matyjaszewski, Adv. Funct. Mater., 2013, 23, 4720-4728.

[45] Y. M. Shen, W. L. Duan, M Shi, Adv. Synth. Catal., 2003, 345, 337-340.

[46] J. Sun, W. G. Cheng, Z. F. Yang, J. Q. Wang, T. T. Xu, J. Y. Xin, S. J. Zhang, Green Chem., 2014, 16, 3071-3078.

[47] K. R. Roshan, R. A. Palissery, A. C. Kathalikkattil, R. Babu, G. Mathai, H. S. Lee, D. W. Park, Catal. Sci. Technol., 2016, DOI: 10.1039/C5CY01902H.

[48] J. A. Kozak, J. Wu, X. Su, F. Simeon, T. A. Hatton, T. F. Jamison, J. Am. Chem. Soc., 2013, 135, 18497-18501.

[49] L. Wang, L. Lin, G. Y. Zhang, K. Kodama, M. Yasutake, T. Hirose, Chem. Commun., 2014, 50, 14813-14816.

[50] L. Wang, K. Kodama, T. Hirose, Catal. Sci. Technol., 2016, DOI: 10.1039/C5CY01892G.

[51] Z. Z. Yang, L. N. He, C. X. Miao, S. Chanfreau, Adv. Synth. Catal., 2010, 352, 2233-2240.

[52] S. Foltran, J. Alsarraf, F. Robert, Y. Landais, E. Cloutet, H. Cramail, T. Tassaing, Catal. Sci. Technol., 2013, 3, 1046-1055.

[53] S. Foltran, R. Mereau, T. Tassaing, Catal. Sci. Technol., 2014, 4, 1585-1597.

[54] K. R. Roshan, T. Jose, D. Kim, K. A. Cherian, D. W. Park, Catal. Sci. Technol., 2014, 4, 963-970.

[55] M. Petkovic, K. R. Seddon, L. P. N. Rebelo, C. S. Pereira, Chem. Soc. Rev., 2011, 40, 1383-1403.

[56] X. P. Zhang, X. C. Zhang, H. F. Dong, Z. J. Zhao, S. J. Zhang, Y. Huang, Energy Environ. Sci., 2012, 5, 6668-6681.

[57] P. P. Pescarmona, M. Taherimehr, Catal. Sci. Technol., 2012, 2, 2169-2187.
[58] Z. Z. Yang, Y. N. Zhao, L. N. He, RSC Adv., 2011, 1, 545-567.

[59] R. C. Luo, X. T. Zhou, Z. Yang, W. Y. Zhang, H. B. Ji, CIESC J., 2016, $67,258-276$.

[60] A. Mirabaud, J. C. Mulatier, A. Martinez, J. P. Dutasta, V. Dufaud, ACS Catal., 2015, 5, 6748-6752.

[61] A. M. Hardman-Baldwin, A. E. Mattson, ChemSusChem, 2014, 7, 3275-3278.

[62] M. Alves, B. Grignard, S. Gennen, R. Mereau, C. Detrembleur, C. Jerome, T. Tassaing, Catal. Sci. Technol., 2015, 5, 4636-4643.

[63] M. E. Wilhelm, M. H. Anthofer, M. Cokoja, I. I. E. Markovits, W. A. Herrmann, F. E. Kühn, ChemSusChem, 2014, 7, 1357-1360.

[64] S. Sopeña, G. Fiorani, C. Martín, A. W. Kleij, ChemSusChem, 2015, 8, 3248-3254.

[65] D. H. Lan, C. T. Au, S. F. Yin, Curr. Green Chem., 2015, 2, 35-42.

[66] X. F. Liu, Q. W. Song, S. Zhang, L. N. He, Catal. Today, 2016, 263, 69-74.

[67] H. Bűttner, K. Lau, A. Spannenberg, T. Werner, ChemCatChem, 2015, 7, 459-467.

[68] L. Wang, P. Li, X. F. Jin, J. L. Zhang, H. Y. He, S. J. Zhang, J. CO Util., 2015, 10, 113-119.

[69] J. Tharun, G. Mathai, R. Roshan, A. C. Kathalikkattil, K. Bomi, D. W. Park, Phys. Chem. Chem. Phys., 2013, 15, 9029-9033.

[70] M. Galvan, M. Selva, A. Perosa, M. Noè, Asian J. Org. Chem., 2014, 3, 504-513.

[71] T. Werner, H. Büttner, ChemSusChem, 2014, 7, 3268-3271.

[72] H. Bűttner, J. Steinbauer, T. Werner, ChemSusChem, 2015, 8, 2655-2669.

[73] W. L. Dai, B. Jin, S. L. Luo, X. B. Luo, X. M. Tu, C. T. Au, Appl. Catal. A, 2014, 470, 183-188.

[74] Y. Li, L. Wang, T. F. Huang, J. L. Zhang, H. Q. He, Ind. Eng. Chem. Res., 2015, 54, 8093-8099.

[75] W. L. Dai, B. Jin, S. L. Luo, X. B. Luo, X. M. Tu, C. T. Au, J. Mol. Catal. A, 2013, 378, 326-332.

[76] H. Zhou, G. X. Wang, W. Z. Zhang, X. B. Lu, ACS Catal., 2015, 5, 6773-6779.

[77] M. H. Anthofer, M. E. Wilhelm, M. Cokoja, I. I. E. Markovits, A. Pöthig, J. Mink, W. A. Herrmann, F. E. Kühn, Catal. Sci. Technol., 2014, 4, 1749-1758.

[78] A. L. Girard, N. Simon, M. Zanatta, S. Marmitt, P. Gonçalves, J. Dupont, Green Chem., 2014, 16, 2815-2825.

[79] S. Marmitt, P. F. B. Goncalves, J. Comput. Chem., 2015, 36, 1322-1333.

[80] L Wang, X. F. Jin, P. Li, J. L. Zhang, H. Y. He, S. J. Zhang, Ind. Eng. Chem. Res., 2014, 53, 8426-8435.

[81] M. S. Liu, K. Q. Gao, L. Liang, F. X. Wang, L. Shi, L. Sheng, J. M. Sun, Phys. Chem. Chem. Phys., 2015, 17, 5959-5965.

[82] M. H. Anthofer, M. E. Wilhelm, M. Cokoja, M. Drees, W. A. Herrmann, F. E. Kűhn, ChemCatChem, 2015, 7, 94-98.

[83] J. Q. Wang, W. G. Cheng, J. Sun, T. Y. Shi, X. P. Zhang, S. J. Zhang, RSC Adv., 2014, 4, 2360-2367.

[84] L. F. Xiao, D. W. Lv, D. Su, W. Wu, H. F. Li, J. Clean. Prod., 2014, 67, 285-290.

[85] L. Wang, X. F. Jin, Y. Li, P. Li, J. L. Zhang, H. Y. He, S. J. Zhang, Mol. Phys., 2015, 113, 3524-3530.

[86] C. T. Yue, D. Su, X. Zhang, W. Wu, L. F. Xiao, Catal Lett., 2014, 144, 1313-1321.

[87] M. S. Liu, L. Liang, X. Li, X. X. Gao, J. M. Sun, Green Chem., 2016, DOI: 10.1039/C5GC02605A.

[88] J. Tharun, K. R. Roshan, A. C. Kathalikkattil, D. H. Kang, H. M. Ryu, D. W. Park, RSC Adv., 2014, 4, 41266-41270.

[89] B. Chatelet, L. Joucla, J. P. Dutasta, A. Martinez, K. C. Szeto, V. Dufaud, J. Am. Chem. Soc., 2013, 135, 5348-5351. 
[90] Z. Q. Zhang, L. C. Xu, W. K. Feng, RSC Adv., 2015, 5, 12382-12386.

[91] B. Chatelet, L. Joucla, J. P. Dutasta, A. Martinez, V. Dufaud, Chem. Eur. J., 2014, 20, 8571-8574.

[92] H. Zhou, Y. M. Wang, W. Z. Zhang, J. P. Qu, X. B. Lu, Green Chem., 2011, 13, 644-650.

[93] F. Adam, M. S. Batagarawa, Appl. Catal. A, 2013, 454, 164-171.

[94] E. A. Prasetyanto, M. B. Ansari, B. H. Min, S. E. Park, Catal. Today, 2010, 158, 252-257.

[95] W. L. Dai, L. Chen, S. F. Yin, S. L. Luo, C. T. Au, Catal. Lett., 2010, 135, 295-304.

[96] W. G. Cheng, X. Chen, J. Sun, J. Q. Wang, S. J. Zhang, Catal. Today, 2013, 200, 117-124.

[97] J. N. Appaturi, F. Adam, Appl. Catal. B, 2013, 136-137, 150-159.

[98] F. Adam, J. N. Appaturi, E. P. Ng, J Mol. Catal. A, 2014, 386, $42-48$.

[99] P. Agrigento, S. M. Al-Amsyar, B. Sorée, M. Taherimehr, M. Gruttadauria, C. Aprile, P. P. Pescarmona, Catal. Sci. Technol., 2014, 4, 1598-1607.

[100] C. Kohrt, T. Werner, ChemSusChem, 2015, 8, 2031-2034.

[101] L. A. Bivona, O. Fichera, L. Fusaro, F. Giacalone, M. Buaki-Sogo, M. Gruttadauria, C. Aprile, Catal. Sci. Technol., 2015, 5, 5000-5007.

[102] Y. Y. Zhang, L. Chen, S. F. Yin, S. L. Luo, C. T. Au, Catal. Lett., 2012, 142, 1376-1381.

[103] Q. Y. Deng, G. H. He, Y. Pan, X. H. Ruan, W. J. Zheng, X. M. Yan, RSC $A d v ., 2016,6,2217-2224$.

[104] V. B. Saptal, B. M. Bhanage, ChemCatChem, 2016, 8, 244-250.

[105] C. J. Whiteoak, A. H. Henseler, C. Ayats, A. W. Kleij, M. A. Pericàs, Green Chem., 2014, 16, 1552-1559.

[106] A. H. Jadhav, G. M. Thorat, K. Lee, A. C. Lim, H. Kang, J. G. Seo, Catal. Today, 2016, 265, 56-67.

[107] W. L. Dai, L. Chen, S. F. Yin, W. H. Li, Y. Y. Zhang, S. L. Luo, C. T. Au, Catal. Lett., 2010, 137, 74-80.

[108] Y. Y. Zhang, S. F. Yin, S. L. Luo, C. T. Au, Ind. Eng. Chem. Res., 2012, 51, 3951-3957.

[109] W. L. Dai, B. Jin, S. L. Luo, X. B. Luo, X. M. Tu, C. T. Au, Catal. Sci. Technol., 2014, 4, 556-562.

[110] W. Zhang, Q. X. Wang, H. H. Wu, P. Wu, M. Y. He, Green Chem., 2014, 16, 4767-4774.

[111] Y. Zhao, J. S. Tian, X. H. Qi, Z. N. Han, Y. Y. Zhang, L. N. He, J. Mol. Catal. A, 2007, 271, 284-289.

[112] J. X. Chen, B. Jin, W. L. Dai, S. L. Deng, L. R. Cao, Z. J. Cao, S. L. Luo, X. B. Luo, X. M. Tu, C. T. Au, Appl. Catal. A, 2014, 484, 26-32.

[113] J. Sun, J. Q. Wang, W. G. Cheng, J. X. Zhang, X. H. Li, S. J. Zhuang, Y. B. She, Green Chem., 2012, 14, 654-660.

[114] J. Tharun, Y. Hwang, R. Roshan, S. Ahn, A. C. Kathalikkattil, D. W. Park, Catal. Sci. Technol., 2012, 2, 1674-1680.

[115] Y. Xie, Z. F. Zhang, T. Jiang, J. L. He, B. X. Han, T. B. Wu, K. L. Ding, Angew. Chem. Int. Ed., 2007, 46, 7255-7258.

[116] T. Y. Shi, J. Q. Wang, J. Sun, M. H. Wang, W. G. Cheng, S. J. Zhang, RSC Adv., 2013, 3, 3726-3732.

[117] L. N. Han, H. J. Choi, D. K. Kim, S. W. Park, B. Y. Liu, D. W. Park, J.
Mol. Catal. A, 2011, 338, 58-64.

[118] A. Dani, E. Groppo, C. Barolo, J. G. Vitillo, S. Bordiga, J. Mater. Chem. A, 2015, 3, 8508-8518.

[119] S. Ghazali-Esfahani, H. B. Song, E. Păunescu, F. D. Bobbink, H. Z. Liu, Z. F. Fei, G. Laurenczy, M. Bagherzadeh, N. Yan, P. J. Dyson, Green Chem., 2013, 15, 1584-1589.

[120] X. C. Wang, Y. Zhou, Z J. Guo, G. J. Chen, J. Li, Y. M. Shi, Y. Q. Liu, J. Wang, Chem. Sci., 2015, 6, 6916-6924.

[121] Y. Leng, D. Lu, P. P. Jiang, C. J. Zhang, J. W. Zhao, W. J. Zhang, Catal. Commun., 2016, 74, 99-103.

[122] Z. Z. Yang, Y. F. Zhao, G. P. Ji, H. Y. Zhang, B. Yu, X. Gao, Z. M. Liu, Green Chem., 2014, 16, 3724-3728.

[123] J. Q. Wang, J. Y. Leong, Y. G. Zhang, Green Chem., 2014, 16, 4515-4519.

[124] J. Q. Wang, J. G. W. Yang, G. S. Yi, Y. G. Zhang, Chem. Commun., 2015, 51, 15708-15711.

[125] J. Roeser, K. Kailasam, A. Thomas, ChemSusChem, 2012, 5, 1793-1799.

[126] X. L. Meng, Y. Nie, J. Sun, W. G. Cheng, J. Q. Wang, H. Y. He, S. J. Zhang, Green Chem., 2014, 16, 2771-2778.

[127] J. H. Yang, D. Yang, P. Tang, D. Ma, Acta Phys. Chim. Sin., 2016, 32, 75-84.

[128] M. B. Ansari, B. H. Min, Y. H. Mo, S. E. Park, Green Chem., 2011, 13, 1416-1421.

[129] Q. Su, J. Sun, J. Q. Wang, Z. F. Yang, W. G. Cheng, S. J. Zhang. Catal. Sci. Technol., 2014, 4, 1556-1562.

[130] Z. J. Huang, F. B. Li, B. F. Chen, T. Lu, Y. Yuan, G. Q. Yuan. Appl. Catal. B, 2013, 136-137, 269-277.

[131] D. H. Lan, H. T. Wang, L. Chen, C. T. Au, S. F. Yin. Carbon, 2016, 100, 81-89.

[132] J. Xu, F. Wu, Q. Jiang, Y. X. Li, Catal. Sci. Technol., 2015, 5, 447-454.

[133] Z. J. Huang, F. B. Li, B. F. Chen, G. Q. Yuan, Catal. Sci. Technol,, 2016, DOI: $10.1039 /$ C5CY01805F.

[134] R. C. Luo, X. T. Zhou, Y. X. Fang, H. B. Ji, Carbon, 2015, 82, 1-11.

[135] V. B. Saptal, T. Sasaki, K. Harada, D. Nishio-Hamane, B. M. Bhanage, ChemSusChem, 2016, DOI: 10.1002/cssc.201501438.

[136] D. H. Lan, L. Chen, C. T. Au, S. F. Yin. Carbon, 2015, 93, 22-31.

[137] J. Xu, M. Xu, J. Wu, H. Wu, W. H. Zhang, Y. X. Li, RSC Adv., 2015, 5, 72361-72368.

[138] W. H. Zhang, P. P. He, S. Wu, J. Xu, Y. X. Li, G. Zhang, X. Y. Wei, Appl. Catal. A, 2016, 509, 111-117.

[139] M. P. Liu, Y. P. Luo, L. Xu, L. Sun, H. B. Du, Dalton Trans., 2016, 45, 2369-2373.

[140] S. Baj, T. Krawczyk, K. Jasiak, A. Siewniak, M. Pawlyta, Appl. Catal. A, 2014, 488, 96-102.

[141] Y. L. Zhang, Z. T. Tan, B. L. Liu, D. S. Mao, C. R. Xiong, Catal. Commun., 2015, 68, 73-76.

[142] X. Y. Ma, B. Zou, M. H. Cao, S. L. Chen, C. W. Hu, J. Mater. Chem. A, 2014, 2, 18360-18366.

[143] Y. Li, B. Zou, C. W. Hu, M. H. Cao, Carbon, 2016, 99, 79-89.

\title{
非金属催化剂在催化环氧化物和 $\mathrm{CO}_{2}$ 合成环状碳酸酯中的研究进展
}

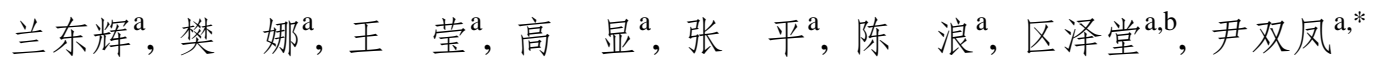 \\ a湖南大学化学化工学院, 湖南长沙 410082

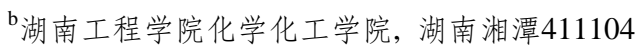

摘要: 随着科学技术的进步和工业化的发展, 大量化石燃料被消耗, 大气中二氧化碳浓度急剧增加, 导致温室效应加剧, 严 重威胁到人类的生存和发展. 基于可持续发展的思想, 利用储量丰富且廉价的二氧化碳作为 C1 资源替代有毒的气体 (如 
一氧化碳和光气等) 制备具有广泛应用的环状碳酸酯, 不仅满足“绿色化学”的要求, 而且符合“原子经济性”的原则. 迄今为 止, 大量用于催化二氧化碳和环氧化物环加成反应合成环状碳酸酯的催化剂, 包括均相催化剂 (如金属卤化物、有机碱、离 子液体和金属配合物), 多相催化剂 (如金属氧化物、负载型催化剂、有机聚合物、金属有机框架材料和碳材料等) 被报道. 其中金属催化剂占主导地位, 大多表现出优异的催化活性. 然而, 目前可供开采的金属矿越来越少, 大多数金属的回收再 利用率较低, 重金属污染日趋严重. 因此, 开发新型、廉价、绿色、高效、循环性和稳定性好的非金属催化剂具有重要意义.

本文主要介绍了近 3 年以来用于催化二氧化碳和环氧化物环加成反应合成环状碳酸酯的非金属催化剂, 主要包括有 机碱、离子液体、固载型催化剂、有机聚合物和碳材料等. 概括了不同种类催化剂的设计思想及其催化反应机理, 重点阐 述了分子内以及分子间各种功能基团的协同作用对环加成反应的影响. 通过比较发现, 具有 “ $C-\mathrm{N}=\mathrm{C}$ ”结构的有机碱活性 相对较高, 氢键给体和亲核物质都能与有机碱协同作用提高其催化活性; 传统离子液体的活性一般不理想, 氢键给体如羟 基和羧基的引入有利于促进环加成反应, 且多阳离子和多氢键给体功能化的离子液体表现出更高的催化活性; 负载型催 化剂中, 载体和活性组分之间的协同作用有利于加速环加成反应的进行, 多种功能基团负载和以共价键方式多层固载能更 好地提高催化剂稳定性和催化活性; 利用非烯烃化合物制得的活性组分位于主链的多孔有机聚合物, 催化活性和稳定性 大多高于活性组分位于侧链的烯烃聚合物; 碳材料催化剂中, 引入不饱和的 $\mathrm{N}$ 物种 (如伯胺和吡啶氮), 有利于 $\mathrm{CO}_{2}$ 的吸附 和活化, 能促进环加成反应. 此外, 利用密度泛函的方法, 计算模拟催化反应过程, 能更好地揭示反应机理, 并为设计和制 备高效的催化剂提供理论指导.

该领域目前面临的重要挑战是研发可以同时实现二氧化碳捕获和转化的新型、环保和高效非金属催化剂, 终极目标是 利用多孔催化材料在常温和常压下直接捕获工业废气中的二氧化碳, 并利用捕获的二氧化碳实现环状碳酸酯的连续生产. 基于协同催化的设计思想, 利用多种基团功能化的策略合成高效吸附和活化二氧化碳以及开环活化环氧化物的非金属催 化剂, 有望实现上述目标.

关键词: 环加成反应; 二氧化碳; 环氧化物; 环状碳酸酯; 非金属催化剂; 协同作用

收稿日期: 2016-03-01. 接受日期: 2016-03-22. 出版日期: 2016-06-05.

*通讯联系人. 电话/传真: (0731)88821171; 电子信箱: sf_yin@hnu.edu.cn

基金来源：国家科技支撑计划(2013BAC11B03); 国家自然科学基金(21401054, 21476065, 21273067); 湖南省研究生科研创新项 目 (CX2015B082).

本文的英文电子版由Elsevier出版社在ScienceDirect上出版(http://www.sciencedirect.com/science/journal/18722067). 